ACCEPTED MANUSCRIPT

\title{
Ion plume investigation of a Hall Effect Thruster operating with $\mathrm{Xe} / \mathrm{N}<\mathrm{sub}>2</$ sub $>$ and Xe/air mixtures
}

To cite this article before publication: Antonio Gurciullo et al 2019 J. Phys. D: Appl. Phys. in press https://doi.org/10.1088/1361-6463/ab36c5

\section{Manuscript version: Accepted Manuscript}

Accepted Manuscript is "the version of the article accepted for publication including all changes made as a result of the peer review process, and which may also include the addition to the article by IOP Publishing of a header, an article ID, a cover sheet and/or an 'Accepted

Manuscript' watermark, but excluding any other editing, typesetting or other changes made by IOP Publishing and/or its licensors"

This Accepted Manuscript is @ 2019 IOP Publishing Ltd.

During the embargo period (the 12 month period from the publication of the Version of Record of this article), the Accepted Manuscript is fully protected by copyright and cannot be reused or reposted elsewhere.

As the Version of Record of this article is going to be / has been published on a subscription basis, this Accepted Manuscript is available for reuse under a CC BY-NC-ND 3.0 licence after the 12 month embargo period.

After the embargo period, everyone is permitted to use copy and redistribute this article for non-commercial purposes only, provided that they adhere to all the terms of the licence https://creativecommons.org/licences/by-nc-nd/3.0

Although reasonable endeavours have been taken to obtain all necessary permissions from third parties to include their copyrighted content within this article, their full citation and copyright line may not be present in this Accepted Manuscript version. Before using any content from this article, please refer to the Version of Record on IOPscience once published for full citation and copyright details, as permissions will likely be required. All third party content is fully copyright protected, unless specifically stated otherwise in the figure caption in the Version of Record.

View the article online for updates and enhancements. 


\title{
Ion plume investigation of a Hall Effect Thruster operating with $\mathrm{Xe} / \mathrm{N}_{2}$ and $\mathrm{Xe} /$ air mixtures
}

\author{
Antonio Gurciullo ${ }^{1} \ddagger$, Andrea Lucca Fabris ${ }^{1}$ and Mark A. \\ Cappelli $^{2}$ \\ 1 Surrey Space Centre, University of Surrey, Guildford, United Kingdom \\ 2 Mechanical Engineering, Stanford University, Stanford, California, USA \\ E-mail: antonio.gurciullo@exotrail.com
}

\begin{abstract}
The ion plume of a $72 \mathrm{~mm}$ diameter Hall Effect Thruster operated on mixtures of xenon/nitrogen and xenon/air is investigated by means of a Wien filter (or $\mathbf{E} \times \mathbf{B}$ probe). The dependence of the velocities of the plume ions $\left(\mathrm{Xe}^{+}\right.$, $\mathrm{Xe}^{2+}, \mathrm{Xe}^{3+}, \mathrm{O}_{2}^{+}, \mathrm{O}^{+}, \mathrm{N}_{2}^{+}$and $\mathrm{N}^{+}$) on the operating parameters of the thruster (anode voltage, anode power, mass flow rate and magnetic field) is explored. The most probable ion acceleration voltages, the ion current and density fractions of the multi-propellant, multi-species ion beam, are computed from the Wien filter spectra through a dedicated post-processing analysis. The knowledge of these properties is fundamental for understanding the contribution of each ion species to the propulsive performance metrics of the thruster when operated on these molecular gas mixtures.
\end{abstract}

Keywords: Wien filter, alternative propellant, Hall Effect Thruster, molecular propellant, ion plume

Submitted to: J. Phys. D: Appl. Phys.

$\ddagger$ Present address: Exotrail, 3 rue Galvani, 91300 Massy, France. 


\section{Introduction}

Electric propulsion has reached a high level of technological maturity and has been adopted as the primary propulsion for planetary and deep space missions [1,2], station keeping [3] and orbit transfer [4]. During the last two decades, a substantial reduction of the cost related to spacecraft manufacturing and launch has made Low Earth Orbit (LEO) accessible to universities and small enterprises. As a consequence, research has shifted toward the development of new propulsion technologies with reduced complexity and cost and the exploration of new applications of the consolidated propulsion systems. For example, with Hall Effect Thrusters (HETs) and Gridded Ion Engines (GIEs), xenon, the commonly used propellant, is highly advantageous in terms of storability, tank mass fraction, and performance when compared to other noble gases. However, its cost is relatively high due to its limited availability and has been significantly fluctuating in the last 40 years due to the uncertainty on xenon demand $[5,6]$. For this reason and also to exploit in-situ propellant resources that might be harvested in orbit (such as air), both industrial and research institutions have been focusing part of their efforts on identifying and investigating a suitable candidate to replace xenon as a propellant. Some promising propellants have emerged, such as iodine $[7,8]$, while others are still under investigation. At the same time, the European Space Agency (ESA) [9-11], the Japanese Aerospace Exploration Agency (JAXA) [12], the National Aeronautics and Space Administration (NASA) [13] and the United States Air Force (USAF) [14] have an interest in or have supported research on air breathing electric propulsion for both Very Low Earth Orbit (VLEO) and planetary applications.

For such VLEO applications of plasma thrusters, Hall Effect Thrusters have been tested with molecular gases, such as $\mathrm{N}_{2}$ and $\mathrm{Xe} / \mathrm{N}_{2} / \mathrm{O}_{2}$ mixtures $[9,15]$, showing a performance deterioration in comparison with the xenon benchmark metrics. This effect can be associated to additional energy losses caused by several processes in the case of molecular propellants, such as vibrational and rotational excitation and dissociation. Similar conclusions have been inferred by a study on a two-stage Helicon Hall Thruster, showing comparable voltage utilisation, lower current utilisation and lower propellant utilisation for nitrogen in comparison with xenon [16]. However, up to now, limited attention has been paid to the ion plume composition and how molecular cracking due to electron impact influences the discharge, and, consequently, thruster performance. This paper addresses this question and, specifically, attempts to quantify the ion species formed during operation of a Hall Effect Thruster propelled with $\mathrm{Xe} / \mathrm{N}_{2}$ and $\mathrm{Xe} / \mathrm{air}$ mixtures and to explain the physical processes that influence the ion plume composition, the exhaust velocities, number density ratios and eurrent ratios of the ions species. The exhaust plume of the Z-70 HET is analysed by means of an ion velocity selector known as a Wien filter, or $\mathbf{E} \times \mathbf{B}$ probe, which allows the estimation of the velocity of the ion species and, if the ion acceleration voltage is similar among the species (as in a HET), to discern the ion species according to their mass-to-charge ratio. Aiming at analysing the composition of the ion beam in terms of mass and charge, we chose to use a Wien filter over a Retarding Potential Analyser (RPA), which is commonly used to measure ion energy distribution functions (IEDFs) $[17,18]$ in plasma thruster plumes. Indeed RPAs fail to discern ion species with similar energy but/different mass-to-charge ratios. Some previous studies $[19,20]$ implemented a combination of RPA and Wien filter measurements in order to provide multiple information on the ion energy along with the ion species composition. In addition to this, raw data acquired by RPAs are usually numerically differentiated in order to obtain the IEDF, a process that amplifies the noise present in the raw data and decreases the accuracy of the measurement $[21,22]$.

\section{Experimental setup}

\subsection{Wien filter}

The Wien filter is a passband velocity filter for charged particles and has been used in electric propulsion since the 70 s to investigate the composition of the plasma plume in Gridded Ion Engines (GIEs) in order to determine the correction factors for thrust, total thrust efficiency and mass utilisation due to multiple charge ions [23,24]. A first attempt to measure the ion energy distribution in a Hall Effect Thruster plume by means of a Wien filter was made by Kim [25] at the end of the 90s. Other works using xenon as the working gas focused on ion species fraction [26] and angularlyresolved spectra studies $[27,28]$. The filter has been also used to compare the performance of annular and cylindrical Hall thrusters [29]. More complex spectra have been detected when molecular gases are used as propellant. Anderson and Fitzgerald investigated the plume composition and molecular fragmentation processes of an arc-discharge ion engine that operated on fullerene [30]. In addition to this, the Wien filter has found application on the detection of positive and negative ions in a radio frequency GIE using sulfur hexafluoride $\left(\mathrm{SF}_{6}\right)$ as the electronegative working gas $[31,32]$.

The Wien filter is formed by assembling together a collimator, an $\mathbf{E} \times \mathbf{B}$ fields region, a drift tube, 


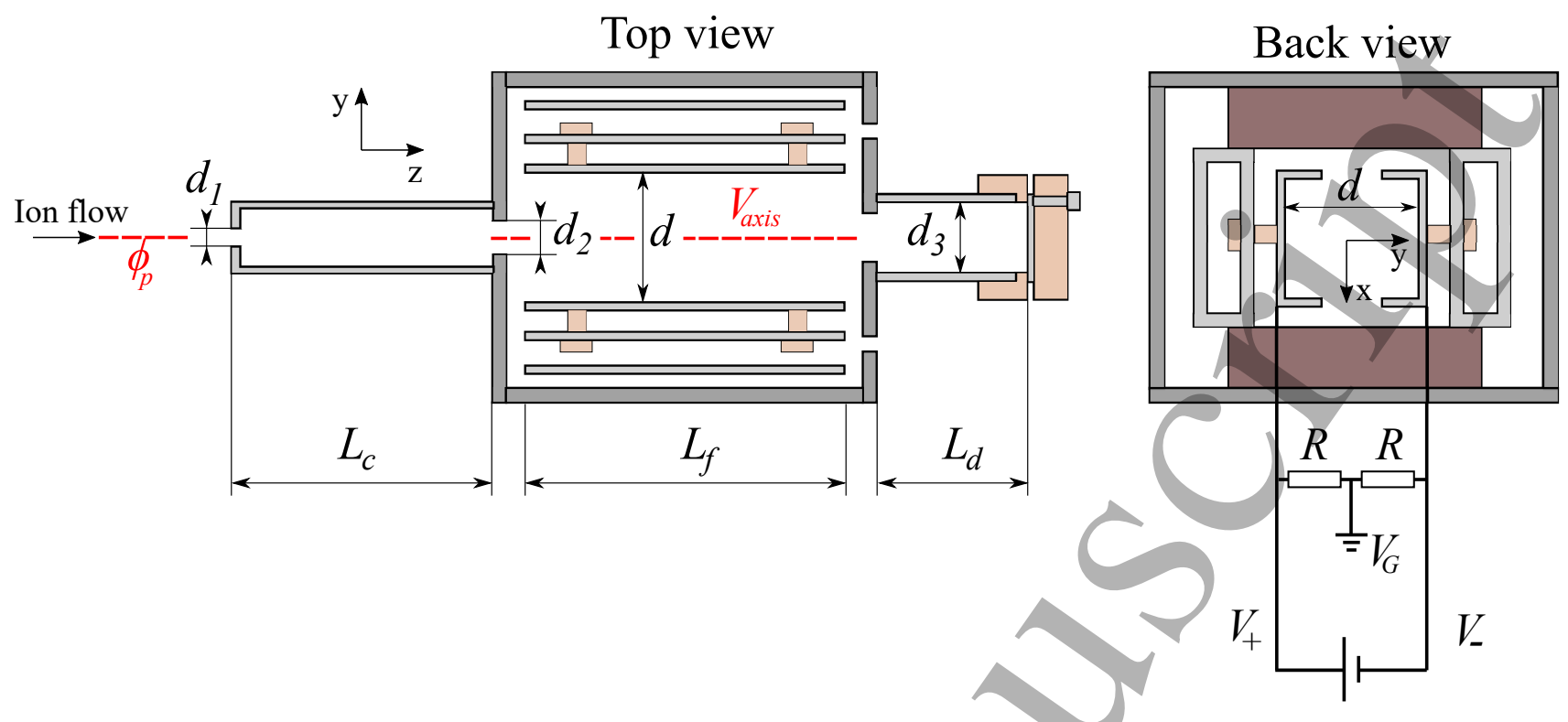

Figure 1: Schematic of the Wien filter showing the collimator, the $\mathbf{E} \times \mathbf{B}$ fields region, the drift tube, the location of the potential $V_{\text {axis }}$ and $\phi_{\mathrm{p}}$, and the voltage divider connected to the plates.

and a collector. The collimator and the drift tube are designed to filter out ions that have a velocity vector that is not parallel to the axis of the Wien filter. In the $\mathbf{E} \times \mathbf{B}$ fields region, an electric field, $\mathbf{E}$, is perpendicular to a magnetic field of magnetic flux density B. The electric field is generated by two parallel plates separated by a distance, $d$, and biased to a potential, $V_{\text {plates }}$. The magnetic field is generated by a pair of permanent magnets. Charged particles that enter the Wien filter travel along the direction perpendicular to $\mathbf{E}$ and $\mathbf{B}$. When the/sum of the external forces acting on the charged particle is null, the particle passes through the filter without any trajectory deviation and with a so-called Wien velocity,

$$
v_{\mathrm{w}}=\frac{E}{B}=\frac{V_{\mathrm{plates}}}{B d} .
$$

Ions with a velocity $v_{\mathrm{w}}$ pass through the drift tube and reach the collector, on which ions are neutralised and their current measured by a picoammeter . In the $\mathbf{E} \times \mathbf{B}$ fields region, both the magnetic field and the distance between the plates are fixed, whereas the potential difference of the plates is controlled by a power supply. In our filter, the magnetic flux density at the centre of the $\mathbf{E} \times \mathbf{B}$ fields region is $0.134 \mathrm{~T}$ and the gap between the plates is $36.5 \mathrm{~mm}$. The potential, $V_{\text {plates }}$, is swept at a constant voltage step of $0.3 \mathrm{~V}$, which allows us to record the Wien velocity spectrum with steps of $\sim 60 \mathrm{~m} / \mathrm{s}$. However, the ion velocity resolution of the filter (half width at half height), $\Delta v$, is linked to the geometry of the filter, to the mass and charge of the ion species, and to the Wien velocity [33], i.e.,

$$
\Delta v=\frac{m v_{\mathrm{w}}^{2}}{Z e B}\left[\frac{d_{2}+d_{3}+\left(d_{1}+d_{2}\right)\left(L_{\mathrm{f}}+L_{\mathrm{d}}\right) / L_{\mathrm{c}}}{L_{\mathrm{f}}^{2}+2 L_{\mathrm{f}} L_{\mathrm{d}}}\right] .
$$

Here $m$ is the ion mass, $e$ is the elementary charge, $Z$ is the ion charge number, $d_{1}$ is the orifice diameter at the entrance of the collimator, $d_{2}$ is the orifice diameter at the exit of the collimator, $d_{3}$ is the diameter at the exit of the drift tube, $L_{\mathrm{c}}$ is the collimator length, $L_{\mathrm{f}}$ is the length of the $\mathbf{E} \times \mathbf{B}$ fields region, and $L_{\mathrm{d}}$ is the length of the drift tube. In our design, $\Delta v=4.67 \cdot 10^{-9} M v_{\mathrm{w}}^{2} /(Z B)$, where $M$ is the mass number of the ion, e.g. 131.29 for Xe. As an example, for singly-ionized $\mathrm{Xe}^{+}$ions with a (Wien) velocity of $15.1 \mathrm{~km} / \mathrm{s}\left(V_{\text {plates }}=74 \mathrm{~V}\right)$, the velocity resolution is about $1 \mathrm{~km} / \mathrm{s}$. For the singly-ionized nitrogen species, $\mathrm{N}_{2}^{+}$and $\mathrm{N}^{+}$, whose velocities are $33.3 \mathrm{~km} / \mathrm{s}\left(V_{\text {plates }}=\right.$ $163 \mathrm{~V})$ and $48 \mathrm{~km} / \mathrm{s}\left(V_{\text {plates }}=235 \mathrm{~V}\right)$, respectively, the velocity resolution is approximately $1.1 \mathrm{~km} / \mathrm{s}$ in both cases. For the species investigated in this paper the ratio $\Delta v / v_{w}$ is $6.6 \%$ for Xe ions, $3.3 \%$ for $\mathrm{N}_{2}^{+}$and $2.3 \%$ for $\mathrm{N}^{+}$.

The schematic of the Wien filter is shown in Figure 1.

In addition to the voltage-sweep technique commonly used in literature [27-29], our approach to determine the ion velocity includes also an additional step that constitutes an element of novelty compared to previous works. This step consists in taking into account of the potential difference between the plasma and the inside (on axis) of the Wien filter $\left(\phi_{\mathrm{p}}-\right.$ $\left.V_{\text {axis }}\right)$ for the computation of the actual velocity of 
ions approaching the filter. This potential difference accelerates the ions and, thus, causes a shift of the Wien filter spectra toward higher values of the plate voltage $\left(V_{\text {plates }}\right)$. The corrected ion velocity is calculated from conservation of ion energy at the entrance of the filter:

$$
v_{\text {ion }}=\sqrt{v_{\mathrm{w}}^{2}-\frac{2 e Z}{m}\left(\phi_{\mathrm{p}}-V_{\mathrm{axis}}\right)} .
$$

Here the Wien velocity $v_{\mathrm{w}}$ is the uncorrected ion velocity. Note that this velocity correction depends on the ion mass and charge. The ratio of the square of the corrected ion velocity to the square of the uncorrected (Wien) velocity is

$$
\frac{v_{\mathrm{ion}}^{2}}{v_{\mathrm{w}}^{2}}=1-\frac{2 e Z}{m v_{\mathrm{w}}^{2}}\left(\phi_{\mathrm{p}}-V_{\mathrm{axis}}\right) .
$$

This allows us to estimate the error in the ion velocity if the potential drop $\left(\phi_{\mathrm{p}}-V_{\text {axis }}\right)$ is not taken into account in the analysis of the data:

$$
\xi_{1}=\frac{v_{\text {ion }}-v_{\mathrm{w}}}{v_{\mathrm{w}}} .
$$

Another source of error that our analysis addresses is the possible potential variation along the Wien filter axis. This is caused by the voltage divider that is used to partition the voltage $V_{\text {plates }}$ between the parallel plates. The voltage divider has the important role to keep the voltage along the Wien filter axis $V_{\text {axis }}$ (along which the ions travel) equal to an imposed voltage $V_{\mathrm{G}}$ :

$$
V_{\mathrm{axis}}=\frac{V_{+}-V_{-}}{2} \equiv V_{\mathrm{G}}
$$

where $V_{+}$and $V_{-}$are the voltages of the positive and negative plates biased with respect to $V_{\mathrm{G}}$, which is the reference potential of the system. However, in reality, the resistors in the voltage divider are not exactly equal and a drift of the axis voltage may be present. This drift is proportional to the potential difference between the plates: $V_{\text {axis }}=C V_{\text {plates }}$, where $C$ in our experimental setup is equal to 0.01 . This drift induces a systematic underestimation of the actual ion velocity that would be recorded if $V_{\text {axis }}=$ const $=0$. The correction factor is found to be:

$$
\frac{v_{\text {ion }}}{\left(v_{\text {ion }}\right)_{V_{\text {axis }}=0}}=\sqrt{1+\frac{\frac{2 e Z}{m} V_{\text {axis }}}{v_{\mathrm{w}}^{2}-\frac{2 e Z}{m} \phi_{\mathrm{p}}}} .
$$

The fractional error in ion velocity can be expressed as:

$$
\xi_{2}=\frac{v_{\text {ion }}-\left(v_{\text {ion }}\right)_{V_{\text {axis }}=0}}{\left(v_{\text {ion }}\right)_{V_{\text {axis }}=0}} .
$$

For the same conditions described above and for a plasma potential of $\phi_{\mathrm{p}}=30 \mathrm{~V}$, the error due to the difference between the plasma potential and filter potential (Equation (5), expressed as a percentage), $\xi_{1}$, for $\mathrm{Xe}^{+}, \mathrm{N}_{2}^{+}$and $\mathrm{N}^{+}$ions is $-10 \%,-9.23 \%$ and $-8.64 \%$, respectively. The negative values indicate that the actual ion velocity is lower than the uncorrected ion velocity (Wien velocity). The error (also in percentage) $\xi_{2}$ is $0.3 \%, 0.6 \%$ and $0.8 \%$, for $\mathrm{Xe}^{+}, \mathrm{N}_{2}^{+}$and $\mathrm{N}^{+}$, respectively. In our analyses of our experimental data below, we take the plasma potential and the drift of the voltage along the Wien filter axis into account, and thus, we calculate the corrected (actual) ion velocity (see (3)) and subsequently, the acceleration voltage that the ion experiences, as

$$
V_{\text {aec }}=\frac{m v_{\text {ion }}^{2}}{2 e Z} .
$$

The uncertainties relative to the ion velocity and ion acceleration/voltage are estimated using a Monte Carlo method $[34,35]$. The ion mass and charge are taken to be known exactly, while the other variables in the model that enter into (3) are only known to a level of uncertainty. A Gaussian probability distribution function (PDF) is assigned to the variables $B, d, \phi_{\mathrm{p}}, C$ and $V_{\text {plates. }}$. The standard deviation, $\sigma$, of the Gaussian PDF satisfies the relation, $3 \sigma=\Delta x$, where $\Delta x$ is the $99.7 \%$ confidence interval of the generic variable $x$. For each variable, $x, 10^{5}$ random samples are simulated from their corresponding Gaussian PDFs.

The uncertainty in the probed current is determined mainly by the uncertainty in the current measured by the Keithley picoammeter model 485, which has an accuracy of $0.4 \%$.

The Wien filter is positioned $30 \mathrm{~cm}$ downstream of the exit of the thruster and a laser is used to align the filter in front of the centreline of the thruster channel. The alignment procedure consists of focusing a laser beam that traverses the Wien filter orifices from the back of the filter (where the collector is installed) to the desired location on the thruster. The field of view of the Wien filter is along the centreline of the thruster's discharge channel, as shown in Figure 2.

\subsection{Langmuir probe}

The plasma potential is measured by a single Langmuir probe. The exposed region of the probe consists of a $2 \mathrm{~mm}$ long, $0.37 \mathrm{~mm}$ diameter tungsten wire. The remaining part of the wire is insulated from the surrounding plasma by an alumina tube, $92 \mathrm{~mm}$ in overall length and $1.3 \mathrm{~mm}$ in its external diameter. The alumina tube runs along the Wien filter body and the probe tip is located about $20 \mathrm{~mm}$ from the filter entrance, a distance much larger than the local Debye length $\left(\lambda_{D} \approx 0.07 \mathrm{~mm}\right)$ preventing mutual influence of the two diagnostics. The probe tip is parallel to the main direction of motion of the ions ejected by the 


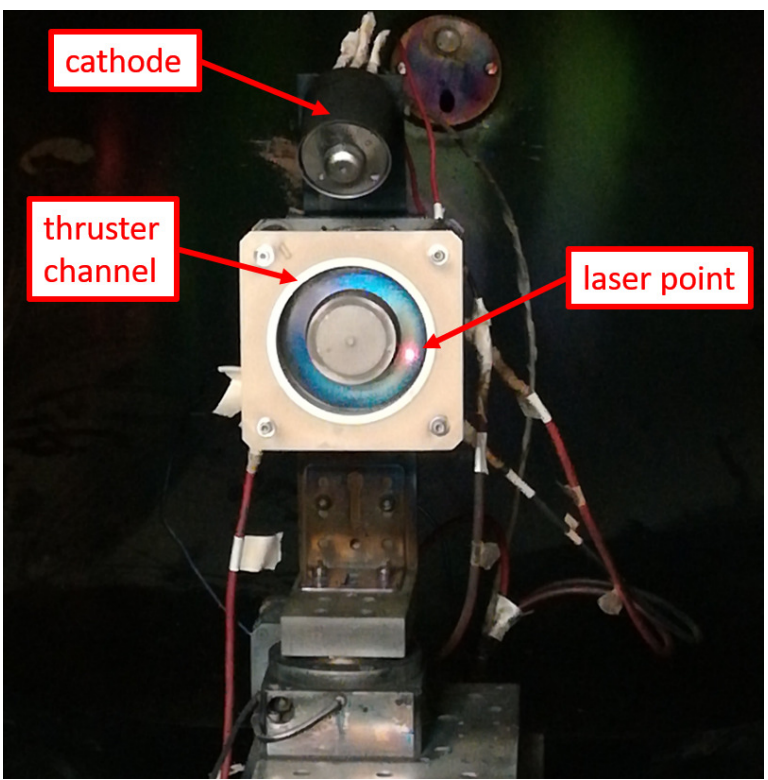

Figure 2: Picture of the Z-70 and cathode during Wien filter alignment.

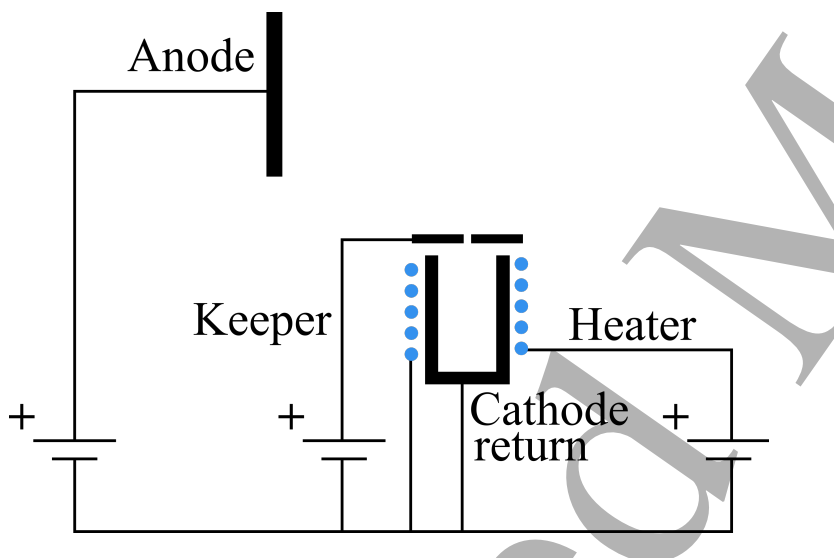

Figure 3: Schematic of the electrical connections.

thruster.

The other extremity of the tungsten wire is clamped to the inner conductor of a coaxial cable which is connected to a BNC terminal. The external conductor of the coaxial cable is floating. The coaxial cable is shielded from the ion bombardment by means of a graphite sheet. A programmable power supply (Kepco model BHK 1000-0.2MG) controls the probe voltage and the probe current is obtained through a transimpedance amplifier. The transimpedance amplifier consists of a shunt resistor of $52 \Omega$ coupled with an operational amplifier (LM318P) circuit. The voltage across the shunt resistor is amplified (by a factor of $\sim 200$ ), resulting in an overall conversion factor of $10.56 \mathrm{mV} / \mathrm{\mu A}$ (output voltage to probe current ratio). A $4.7 \mu \mathrm{F}$ capacitor is placed in parallel to a $630 \mathrm{k} \Omega$ feedback resistor in order to filter out oscillations above $50 \mathrm{~Hz}$. Both the probe voltage and the transimpedance amplifier output voltage are monitored by an oscilloscope (Tektronix model TDS5054B), the waveforms of which are acquired using LabVIEW and stored digitally. The files are subsequently processed using Matlab scripts.

\subsection{Thruster and cathode}

A picture of the Hall Effect Thruster used in this work, labelled as Z-70 thruster, is shown in Figure 2. Prior to our studies, some thruster components were refurbished or replaced with new ones, such as the channel walls, internal ceramic parts and the electromagnet wires. The ceramic channel walls are made of grade AX boron nitride. The channel has an outer diameter of $72 \mathrm{~mm}$, an inner diameter of $42 \mathrm{~mm}$ and a depth of $23 \mathrm{~mm}$. The channel centreline has a radius of $28.5 \mathrm{~mm}$ (measured from the centre of the thruster). The thruster is operated with mixtures of xenon and a second gas, at various flow rates. The electromagnets are powered at a current of $1.5 \mathrm{~A}$, which gives a measured radial magnetic flux density of $135 \mathrm{G}$ at the channel centreline on the exit plane. An IonTech model HC-252 cathode with a barium oxide emitter is used to sustain the discharge and neutralize the resulting ion beam. The cathode is operated with Xe at a flow rate of $0.46 \mathrm{mg} / \mathrm{s}$. More details about the magnetic field topology and thruster operation can be found in the thesis of Smith [36]. The schematic of the electrical configuration of the Z-70 and cathode is shown in Figure 3. This thruster is optimised to operate with xenon and it is expected that the use of molecular propellant lowers the propulsive performance. Nevertheless, the main objective of this study is to investigate the ion plume composition of a HET operating with molecular propellants, rather than to estimate (or optimise) the thruster's performance metrics, as detailed in the thesis of Gurciullo [37].

\subsection{Vacuum facility, power and propellant management}

The experiments are performed at Stanford University in a $4 \mathrm{~m}$ long, $1.5 \mathrm{~m}$ diameter stainless steel vacuum chamber equipped with a two-stage cryogenic pumping system consisting of two opposing shrouds cooled with a Polycold Fast Cycle Water Vapour Cryopump (PFC, Model 1100) and two cryopanels cooled with cryogenic helium. The typical base pressure is $5 \cdot 10^{-7}$ Torr and the background neutral pressure is $6.5 \cdot 10^{-5}$ Torr (not corrected for xenon) while the thruster and cathode are in operation at an overall xenon mass flow rate of $2.4 \mathrm{mg} / \mathrm{s}$. The facility pressure was measured on the lateral wall of the cylindrical chamber approximately 
$1.5 \mathrm{~m}$ downstream of the thruster using an ion gauge (uncorrected for xenon). It is noteworthy that the background pressure in our facility, based on the value measured at the location of the pressure gauge, exceeds that recommended in the guidelines identified by Dankanich [38]. As demonstrated in past studies, background pressure can influence several factors, such as operating conditions, discharge properties, oscillatory modes, plume properties and thruster performance [39-42]. Specifically, in our study we are measuring axial ion velocities using a Wien filter located $30 \mathrm{~cm}$ from the exit plane of the thruster; in this location ions have already undergone full acceleration and reached the ultimate velocity. A recent analysis on the effect of background pressure on xenon ion velocity distribution functions in a SPT-100 Hall Thruster [43] has shown that rising the pressure mainly shifts the location of the peak ionisation region and acceleration front upstream toward the anode, however the ultimate ion velocity (occurring few centimeters maximum from the exit plane) appears unaffected. Other studies on background pressure effects on Hall Thruster operation with xenon have shown a decrease of the most probable ion energy, broadening of the ion energy distribution, and rise of the relative amount of the multiplycharged species (until levelling off) with increasing background pressure $[44,45]$. Background pressure has also an impact on discharge stability that, in turn, can influence the width of the ionization zone resulting in a broadening of the ion energy distribution [45].

An UltraFlow model UC2-21S02 mass flow controller is used for molecular propellant delivery to the thruster and two Unit Instruments Inc. model UFC-1200A controllers regulate the xenon flows to the thruster and the cathode. The molecular propellant and $\mathrm{Xe}$ are mixed downstream of the mass flow controllers. All controllers are connected to a Unit Instruments Inc. model URS-100 readout.

The anode of the thruster is connected to a Power Ten Inc. DC power supply $(300 \mathrm{~V}, 6.6 \mathrm{~A})$. The cathode keeper is connected to a Sorensen DCS600-1.7E DC power supply $(600 \mathrm{~V}, 1.7 \mathrm{~A})$. Two Sorensen DLM40-15 (40V, 15A) DC power supplies are used for the cathode heater and thruster electromagnet, respectively. The ion current collected by the sensor within the Wien filter is measured by a Keithley/picoammeter model 485 (0.4\% reading accuracy) and a Sorensen XG600$1.4(600 \mathrm{~V}, 1.4 \mathrm{~A})$ power supply is programmed to sweep the plate voltage.

\section{Wien Filter Analysis}

The raw Wien filter spectra (ion current at the collector versus plate voltage $\left.\left(V_{\text {plates }}\right)\right)$ are usually smooth, since an averaging process is already included in
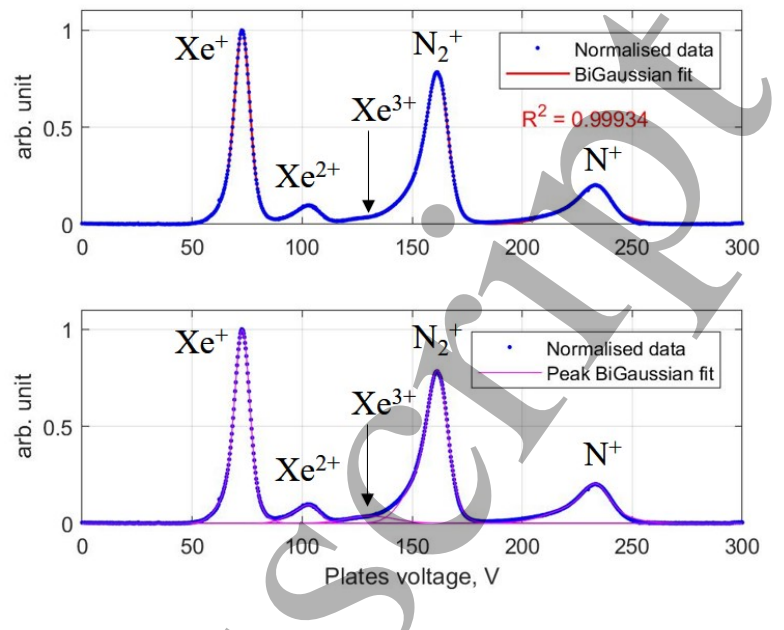

Figure 4: Example of Wien filter spectrum (blue dots) and fitting curves of the overall spectrum (red) and single peaks (magenta).

the data acquisition method, i.e. for each voltage, $V_{\text {plates, }}$ three ion current values are collected and averaged. Those Wien filter spectra that have their baseline above zero are shifted so that the baseline coincides with the horizontal axis. Similar to the method used by Huang and Shastry [33], the Wien filter spectra are fitted to several distribution function sets, namely Gaussian, variable exponent, BiGaussian and skew-normal distribution functions. The set of distribution functions that best fits the experimental spectra appeared to be the BiGaussian:

$$
\begin{aligned}
& S_{\mathrm{BG}}= \\
& \sum_{k=1}^{N_{p}}\left\{a_{1, k} \exp \left[-\left(\frac{V_{\text {plates }}-b_{1, k}}{\sqrt{2} c_{1, k}}\right)^{2}\right]+\right. \\
& a_{2, k} \exp \left[-\left(\frac{V_{\text {plates }}-b_{2, k}}{\sqrt{2} c_{2, k}}\right)^{2}\right] \text {. }
\end{aligned}
$$

Here $a_{1, k}, \quad a_{2, k}, \quad b_{1, k}, \quad b_{2, k}, \quad c_{1, k}$ and $c_{2, k}$ are the fitting coefficients of the $k$-th peak and $N_{\mathrm{p}}$ is the number of peaks. These coefficients are fitted within a 95\% confidence level. After the fitting procedure, the coefficient of determination $\left(\mathrm{R}^{2}\right)$ is reviewed and the spectrum $S_{\mathrm{BG}}$ is compared to that obtained experimentally.

An example result of the fitting process is shown in Figure 4. In this example, the thruster is operated with a Xe/ $\mathrm{N}_{2}$ mixture with $\mathrm{Xe}$ and $\mathrm{N}_{2}$ mass flow rates of $0.49 \mathrm{mg} / \mathrm{s}$ and $0.69 \mathrm{mg} / \mathrm{s}$, respectively. The anode voltage is $290 \mathrm{~V}$, anode current is $1.14 \mathrm{~A}$, and the background pressure is $4.5 \cdot 10^{-5}$ Torr (gauge not corrected for the $\mathrm{Xe} / \mathrm{N}_{2}$ mixture). The top panel is the experimental spectrum (in blue, normalized to the 
most intense peak) as well as the aggregate fit (in red) resulting from the analysis procedure described above. The lower panel is the raw data (in blue) with underlying BiGaussian fits to each peak (magenta). From left to right, the five peaks correspond to $\mathrm{Xe}^{+}$, $\mathrm{Xe}^{2+}, \mathrm{Xe}^{3+}$ (very small in amplitude), $\mathrm{N}_{2}^{+}$and $\mathrm{N}^{+}$. As it is confirmed by both a visual inspection of the single peak fit curves (magenta, lower panel), the aggregate fit (red line in the upper panel) and the value of the coefficient of determination $\left(\mathrm{R}^{2}\right)$, the set of BiGaussian distribution functions fit the Wien filter spectrum extremely well.

The Wien filter spectra can be used to estimate the ratio of ion densities and currents [33]. In our analysis, these ratios take into account the different mass, charge and acceleration voltage of the various ion species. The number density ratio of the $k$-th species in a multipropellant multi-species plasma can be expressed as:

$$
\zeta_{k}=\frac{n_{k}}{\sum_{j} n_{j}}=\frac{\frac{1}{m_{k}} \int_{0}^{\infty} \frac{I_{p, k}\left(V_{\text {plates }}\right)}{V_{\text {plates }}^{3}} d V_{\text {plates }}}{\sum_{j} \frac{1}{m_{j}} \int_{0}^{\infty} \frac{I_{p, j}\left(V_{\text {plates }}\right)}{V_{\text {plates }}^{3}} d V_{\text {plates }}} .
$$

The ion current ratio for the $\mathrm{k}$-th species in a multipropellant multi-species plasma is:

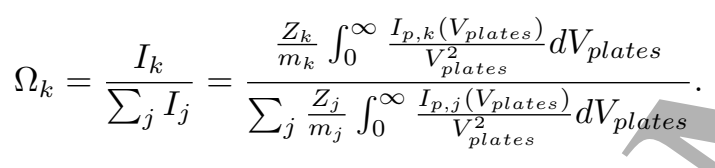

The extended derivations of the formulae above can be found in the thesis of Gurciullo [37]. Here, $k$ and $j$ are variables used to define the $k$-th and the $j$-th ion species present in the Wien filter spectrum, respectively, $n_{k}$ is the ion density, $I_{k}$ is the ion current at the entrance of the filter, $Z_{k}$ is the ion charge number, $m_{k}$ is the ion mass, $I_{\mathrm{p}, k}$ is the contribution of the $k$-th ion species to the ion current collected by the Wien filter collector, and $V_{\text {plates }}$ is the potential difference between the plates within the filter.

\section{Results and discussion}

The Z-70 HET has been tested with Xe, Xe/ $\mathrm{N}_{2}$ mixture and $\mathrm{Xe} /$ air mixture. Figure 5 shows a picture of the thruster while in operation. The list of runs and the related operating parameters of the thruster (mass flow rate, anode voltage and power) are shown in Table 1. The run numbering follows that of the full database found in the appendix of the thesis of Gurciullo [37]. It is worth noting that a certain amount of xenon was needed in order to maintain a stable discharge. In the case of $\mathrm{Xe} / \mathrm{N}_{2}$ mixtures, if the xenon flow rate is decreased below $0.16 \mathrm{mg} / \mathrm{s}(\mathrm{XeN} 2-16)$ and the anode voltage is not increased above $290 \mathrm{~V}$, the discharge becomes unstable and instantaneously quenches. A
Table 1: Operating parameters of the thruster at various runs.

\begin{tabular}{lccccc}
\hline Run & $\begin{array}{c}\dot{m}_{\mathrm{Xe}} \\
{[\mathrm{mg} / \mathrm{s}]}\end{array}$ & $\begin{array}{c}\dot{m}_{\mathrm{N}_{2}} \\
{[\mathrm{mg} / \mathrm{s}]}\end{array}$ & $\begin{array}{c}\dot{m}_{\mathrm{air}} \\
{[\mathrm{mg} / \mathrm{s}]}\end{array}$ & $\begin{array}{c}V_{a} \\
{[\mathrm{~V}]}\end{array}$ & $\begin{array}{c}P_{a} \\
{[\mathrm{~W}]}\end{array}$ \\
\hline XeN2-1 & 1.97 & 0 & - & 290 & 565.5 \\
XeN2-2 & 1.97 & 0 & - & 270 & 491.4 \\
XeN2-5 & 1.63 & 0.21 & - & 290 & 681.5 \\
XeN2-7 & 0.99 & 0.46 & - & 290 & 426.3 \\
XeN2-8 & 0.99 & 0.46 & - & 270 & 394.2 \\
XeN2-9 & 0.90 & 0.82 & - & 290 & 681.5 \\
XeN2-10 & 0.80 & 0.82 & - & 290 & 603.2 \\
XeN2-11 & 0.67 & 0.82 & - & 290 & 524.9 \\
XeN2-12 & 0.67 & 0.92 & - & 290 & 603.2 \\
XeN2-13 & 0.67 & 1.01 & - & 290 & 681.5 \\
XeN2-15 & 0.16 & 1.33 & - & 290 & 603.2 \\
XeN2-16 & 0.16 & 1.39 & - & 290 & 681.5 \\
XeAir-1 & 1.97 & - & 0 & 290 & 571.3 \\
XeAir-2 & 1.97 & - & 0.09 & 290 & 730.8 \\
XeAir-3 & 0.78 & - & 0.83 & 290 & 745.3 \\
XeAir-4 & 0.78 & - & 0.83 & 290 & 710.5 \\
\hline
\end{tabular}

similar discussion is valid for the Xe/air case. Since we were limited by the anode voltage provided by the power supply, it was not possible to switch to a pure $\mathrm{N}_{2}$ or air discharge.

\subsection{Xe only}

A representative spectra acquired when only xenon is the working gas is shown in Figure 6. The operational conditions are as follows: the xenon mass flow rate is $1.97 \mathrm{mg} / \mathrm{s}$ at two different anode voltages, namely $290 \mathrm{~V}$ in run XeN2-1 (red line) and $270 \mathrm{~V}$ in run XeN2-2 (blue line). Three well-pronounced peaks are observed which correspond to $\mathrm{Xe}^{+}, \mathrm{Xe}^{2+}$ and $\mathrm{Xe}^{3+}$. At a higher anode voltage (and anode power) the three peaks have higher amplitudes than those at a lower anode voltage in accordance with a higher overall ion current. At $290 \mathrm{~V}$ the most probable (uncorrected) ion velocities are $14 \mathrm{~km} / \mathrm{s}\left(V_{\text {plates }}=71.9 \mathrm{~V}\right), 20 \mathrm{~km} / \mathrm{s}\left(V_{\text {plates }}=\right.$ $102.2 \mathrm{~V})$ and $26 \mathrm{~km} / \mathrm{s}\left(V_{\text {plates }}=124.7 \mathrm{~V}\right)$ for $\mathrm{Xe}^{+}$, $\mathrm{Xe}^{2+}$ and $\mathrm{Xe}^{3+}$, respectively. At an anode voltage of $270 \mathrm{~V}$ the ion velocities are $13 \mathrm{~km} / \mathrm{s}\left(V_{\text {plates }}=69 \mathrm{~V}\right)$, $19 \mathrm{~km} / \mathrm{s}\left(V_{\text {plates }}=97.7 \mathrm{~V}\right)$ and $23 \mathrm{~km} / \mathrm{s}\left(V_{\text {plates }}=\right.$ $119.3 \mathrm{~V})$ for $\mathrm{Xe}^{+}, \mathrm{Xe}^{2+}$ and $\mathrm{Xe}^{3+}$, respectively. Note that the ratio of the $k$-th ion velocity with respect to that of $\mathrm{Xe}^{+}$is approximately equal to the square root of the charge number of the $k$-th ion, i.e. $\sqrt{Z_{k}}$, a result that matches prediction from theory. The estimated velocity and acceleration voltage of the three ion species are shown in Figure 7 and Figure 8. The results suggest that the ions are created at the same potential within the discharge channel, despite that 


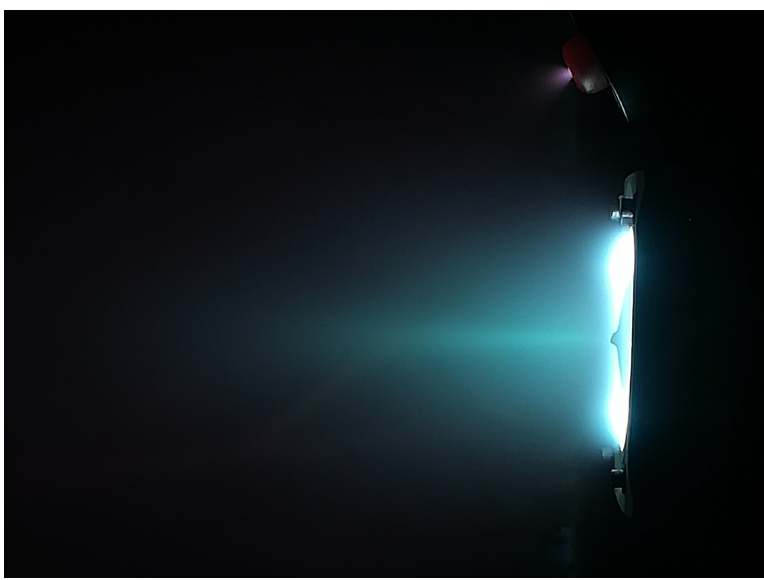

(a)

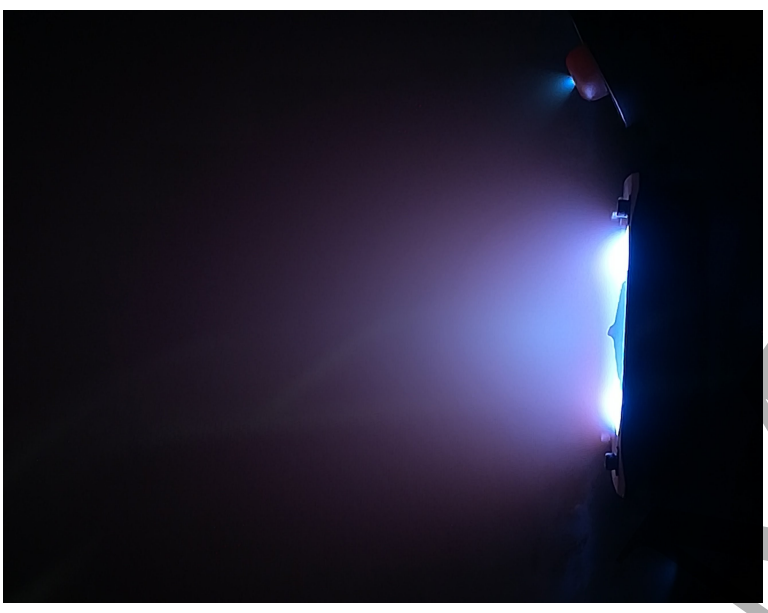

(b)

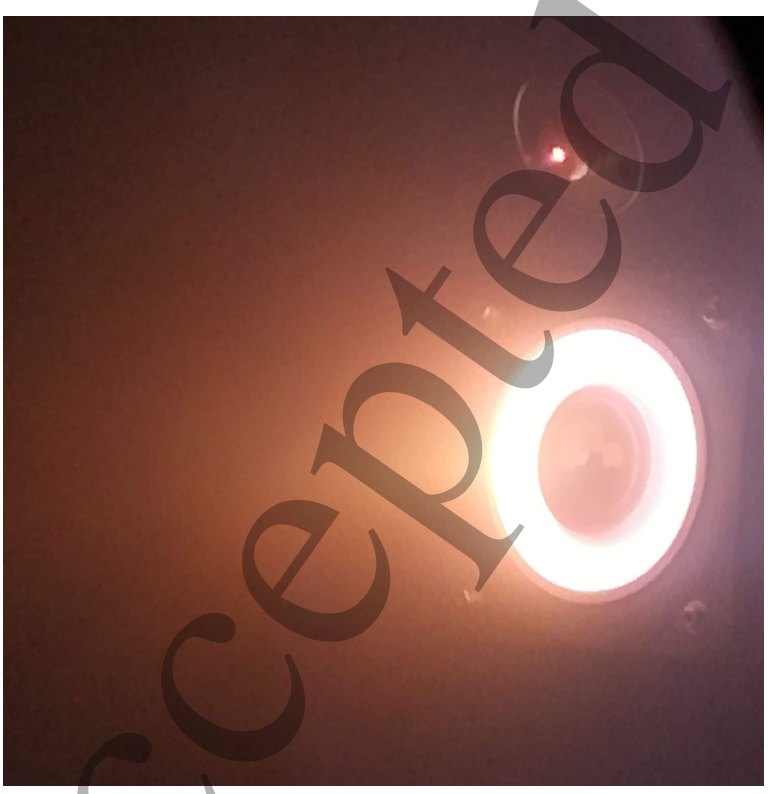

(c)

Figure 5: Pictures of the Z-70 Hall Effect Thruster while in operation with (a) Xe, (b) Xe/ $\mathrm{N}_{2}$ mixture and (c) Xe/air mixture.

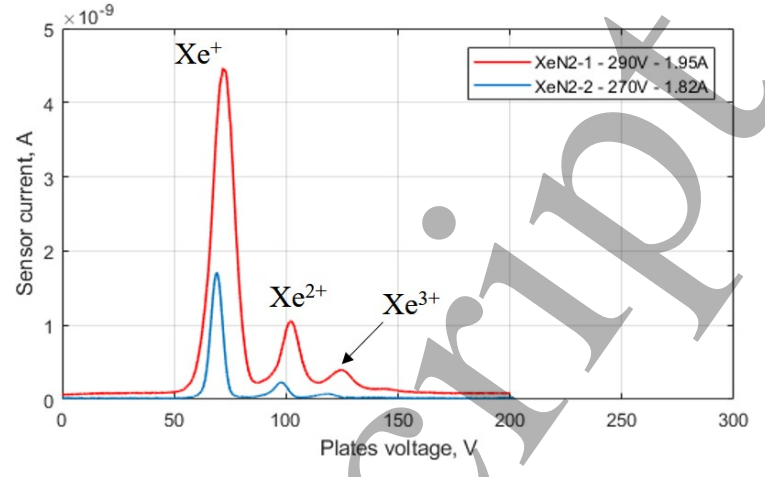

Figure 6: Run number XeN2-1 and XeN2-2 at only xenon flow rate of $1.97 \mathrm{mg} / \mathrm{s}$ at two different anode voltages.

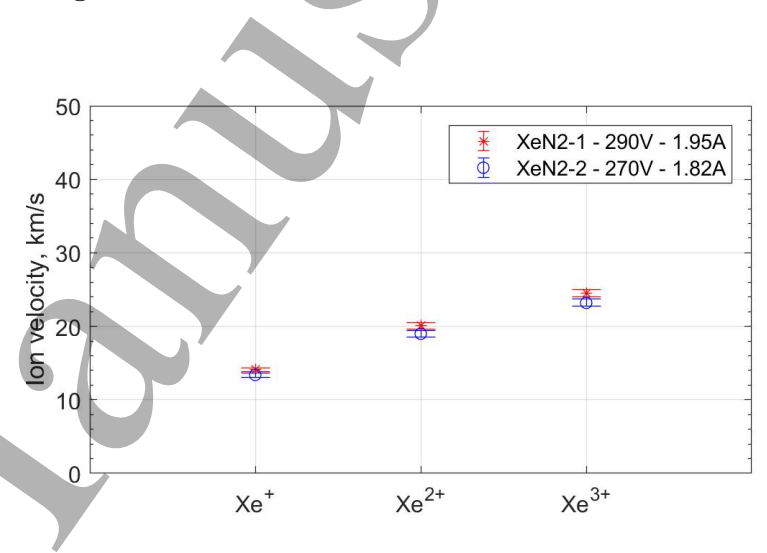

Figure 7: Ion velocity derived from the XeN2-1 and XeN2-2 spectra: xenon mass flow rate of $1.97 \mathrm{mg} / \mathrm{s}$ and two different anode voltages. The legend shows the anode voltage and current.

the potential distribution in space is highly dynamic $[46,47]$. The velocity of the xenon ion species is in agreement with other experimental results obtained on the same thruster using laser-based velocimetry [46]. In order to accomplish this comparison with previous published data, the thruster has been operated at conditions similar to that investigated in [46]. As suggested by the results in Figure 8, at this operating point the voltage utilisation efficiency is lower than the reference values for Hall Effect Thrusters [48]. Since the aim of the study is to identify a general trend of the ion plume composition and ion velocities as functions of macroscopic parameters, such as anode voltage, magnetic field and gas composition and flow rate, the low voltage efficiency should not limit the validity of the identified general trends.

\section{2. $\mathrm{Xe} / \mathrm{N}_{2}$ mixture}

Operation of the thruster on $\mathrm{Xe} / \mathrm{N}_{2}$ mixtures was studied extensively, varying gas flow rates and anode 


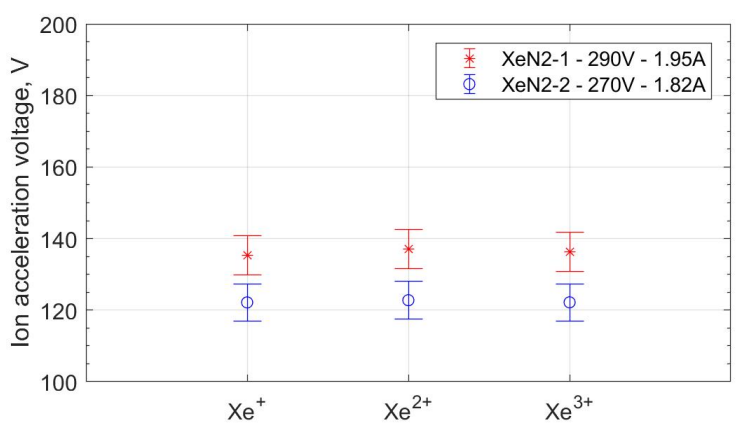

Figure 8: Ion acceleration voltage derived from the XeN2-1 and XeN2-2: xenon mass flow rate of $1.97 \mathrm{mg} / \mathrm{s}$ and two different anode voltages. The legend shows the anode voltage and current.

power. The main ion species detected by the Wien filter are $\mathrm{Xe}^{+}, \mathrm{Xe}^{2+} \mathrm{Xe}^{3+} \mathrm{N}_{2}^{+}$and $\mathrm{N}^{+}$. Since the filter is a velocity discriminator, it cannot distinguish species having the same mass-to-charge ratio and this would preclude distinguishing between the $\mathrm{N}_{2}^{2+}$ and $\mathrm{N}^{+}$species. However, previous ionisation cross-section studies concluded that the ionisation cross section of $\mathrm{N}_{2}$ for $\mathrm{N}_{2}^{2+}$ production is from one to three orders of magnitude lower than the ionisation cross section for the production of $\mathrm{N}^{+}$, depending on the electron energy [49-51]. For example, at an electron energy of $50 \mathrm{eV}$, the partial ionisation cross sections of molecular nitrogen $\left(\mathrm{N}_{2}\right)$ for the production of $\mathrm{N}^{+}$and $\mathrm{N}_{2}^{2+}$ are $1.6 \cdot 10^{-21} \mathrm{~m}^{2}$ and $0.006 \cdot 10^{-21} \mathrm{~m}^{2}$, respectively [49]. Thus, it is expected that the $\mathrm{N}_{2}^{2+} / \mathrm{N}^{+}$peak in the Wien spectra is mainly populated by $\mathrm{N}^{+}$and the presence of $\mathrm{N}_{2}^{2+}$ is negligible.

\subsubsection{Effect of the anode power. The spectra in} Figure 9 show the effect of the anode voltage on the plume composition. The $\mathrm{Xe}$ and $\mathrm{N}_{2}$ flow rates are kept constant: $0.99 \mathrm{mg} / \mathrm{s}$ of $\mathrm{Xe}$ and $0.46 \mathrm{mg} / \mathrm{s}$ of $\mathrm{N}_{2}$. In general, at an anode voltage of $290 \mathrm{~V}$ (red line), higher peak values and higher ion velocities are observed than in the case at $270 \mathrm{~V}$ (blue line). This increase in ion velocity is expected when the anode voltage raises, since the voltage of the ion acceleration region within the Hall Effect Thruster directly depends on the anode voltage.

As shown in Figure 10, based on the measured acceleration voltage, we see that $\mathrm{N}_{2}^{+}$and $\mathrm{N}^{+}$are accelerated to higher energies than those of the family of xenon ions. This would suggest that the lighter ions are created in a further upstream region where the potential is higher. This is somewhat counterintuitive, as the electron impact ionisation cross section of $\mathrm{N}_{2}$ is lower than that of xenon, and furthermore, we expect the $\mathrm{N}_{2}$ flow residence time within the

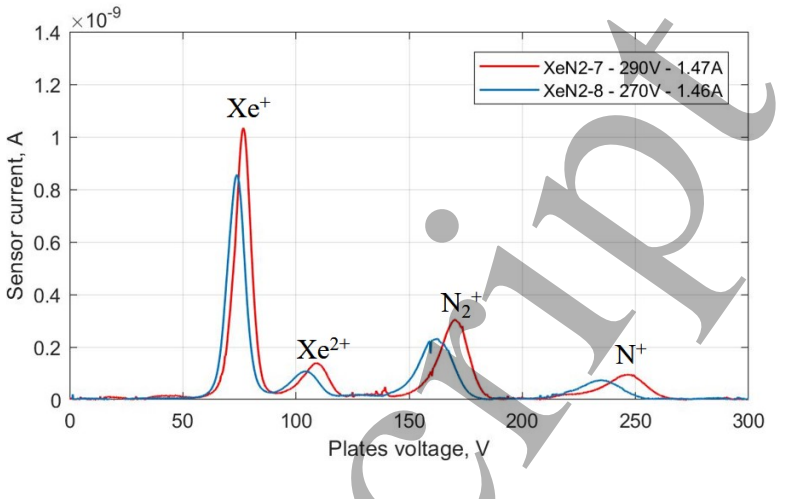

Figure 9: Uncorrected Wien filter spectra at fixed mass flow rate ratio $\left(0.99 \mathrm{mg} / \mathrm{s}\right.$ of Xe and $0.46 \mathrm{mg} / \mathrm{s}$ of $\left.\mathrm{N}_{2}\right)$ and increased discharge voltage. On the top right corner of the plot, the legend shows the experiment number and the anode voltage.

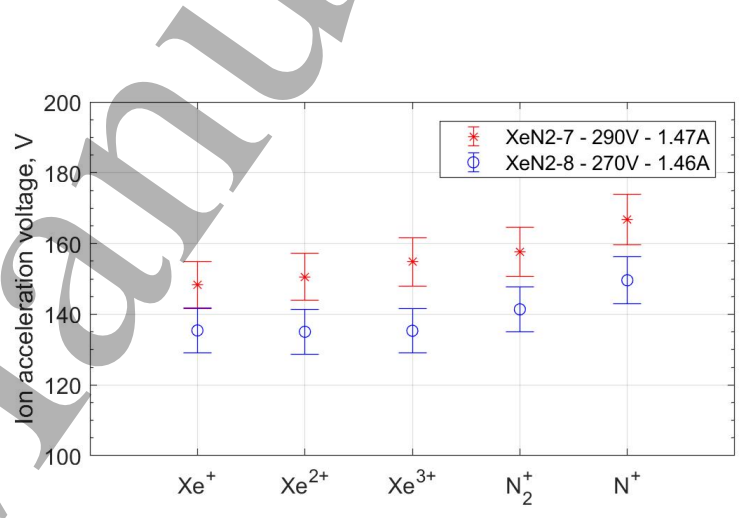

Figure 10: Ion acceleration voltage derived from the XeN2-7 and XeN2-8 spectra: fixed mass flow rate ratio $\left(0.99 \mathrm{mg} / \mathrm{s}\right.$ of Xe and $0.46 \mathrm{mg} / \mathrm{s}$ of $\left.\mathrm{N}_{2}\right)$ and increased discharge voltage. The legend shows the anode voltage and current.

ionisation region to be much shorter than that of the heavier Xe atoms. Further investigation is needed in order to isolate the cause of this observation. We suggest exploring the discharge dynamics of molecular propelled thrusters and corroborating whether current and voltage oscillations have an impact on the ion energy of molecular propelled thrusters. A similar trend has been also observed using Xe/air mixtures, i.e. lighter ions seem to be accelerated at higher voltages. Wien filter measurements for these Xe/air cases are presented in Section 4.3 along with details on discharge current oscillations and associated features in frequency domain (Figure 25). Another possible cause we have explored is whether a long-term drift of the plasma properties could have impacted the acquired data during the time interval needed to complete a voltage scan in the Wien filter (a scan can take up to 40 minutes). The investigated hypothesis is whether 
the plasma conditions during the acquisition of the Xe-family peaks (at lower voltage) might be partially different from those during the acquisition of $\mathrm{N}_{2}^{+}$and $\mathrm{N}^{+}$peaks (at higher voltage), notwithstanding all the macroscopic parameters of the thruster (mass flows, anode voltage and current) remain constant. Scans of the Wien filter spectra have been performed both when the initial plate voltage difference, $V_{\text {plates }}$, is zero (full spectrum scan) and when it is closer to the left slope of the $\mathrm{N}_{2}^{+}$peak (above the voltage of all the Xe peaks, partial spectrum scan). In the high voltage region of the spectra, no significant difference between the full and the partial sweeps is observed suggesting that, together with the Langmuir probe measurements in the plume, the plasma conditions change within uncertainty and have a low impact on the portion of the spectra containing nitrogen and oxygen peaks. We exclude that a long exposure to the plasma plume has an important effect on the Wien filter probe operation conditions. In order to minimise the heat flux deposition on the probe, the front of the Wien filter is protected by graphite sheets. Only the entrance of the collimator tube is directly exposed to the ion plume. As it has been analysed by Reid et al. [28], the probe temperature can increase throughout the experiment which may lead to a decrease of the permeability of the filter's magnetic circuit over time. Given the precaution and inspections we have implemented, even if direct temperature measurements on our probe have been not performed, we believe that an eventual probe temperature change has a negligible effect on the data here presented. Using a conservative approach, the temperature coefficient of the remanent induction and the intrinsic coercivity of the magnets are $-0.03 \% / \mathrm{K}$ and $+0.03 \% / \mathrm{K}$, respectively. An increase of $60 \mathrm{~K}$ causes a decrease of the magnetic field within the filter of less than $1 \%$, a value smaller than the $5.4 \%$ change needed in order to cause a velocity shift whose magnitude is similar to that observed in our experiment. Moreover, Reid et al. [28] have measured a maximum magnets temperature between $340 \mathrm{~K}$ and $380 \mathrm{~K}$ while testing a $6 \mathrm{~kW}$ thruster. Given that the design of our Wien filter is similar to theirs (similar thermal capacity), the probe has been shielded from direct ion bombardment (except the collimator entrance) and the Z-70 thruster has been operated between 400 and $750 \mathrm{~W}$ (thus, a lower thermal flux than that expected in Reid's study), the expected maximum temperature within our probe is lower than that measured by Reid. Before the first Wien filter scan, the thruster has been operated for about 40 minutes, a time considered sufficient to reach thermal stability at the anode and dielectric channel of the thruster. This interval is determined by the amount of time needed to reach the equilibrium electromagnet voltage during discharge and it is in agreement with results published in literature [52]. Moreover, Wien filter spectra using only xenon as propellant have been acquired at the beginning and at the end of the test campaign, showing none or negligible drift on the data. In addition to this, if the temperature rise would have substantially decreased the permeability of the Wien filter magnetic circuit and caused a decrease of the magnetic field, according to equation (1) a same Wien velocity would have been recorded at lower potential bias $V_{\text {plates }}$, a case not encountered during our tests and in contrast to our findings relative to the lighter ion species. In order to minimise neutral pressure build-up inside the filter, two $1 \mathrm{~cm}$ diameter holes are bored at the back plate, similarly to the Wien filter used by Kim [25], who demonstrated that the neutrals build-up inside the filter has a negligible effect on ion energy measurements. A final hypothesis on the species-dependent ion energy can be formulated on the basis of stepwise ionisation, i.e. driven by subsequent excitation events, that might increase the probability of ionisation of $\mathrm{N}_{2}$ in a location at higher potential than that of formation of Xe ions. Depending on the discharge conditions, different electron-impact collision processes take place leading to excitation of neutrals to intermediate excited states at various energy/levels before achieving ionisation. Local excited state population dynamics is determined by a complex physical interplay between collisional-radiative mixing and local transport mechanisms [47, 53]. These processes are species-dependent, possibly causing a shift of the ionisation regions of the different species. Further investigation is required in order to reach a conclusion and to confirm the presented hypothesis. In future characterisations, it might be possible to use a different approach to explain these results, including non-intrusive diagnostic methods, such as spatially-resolved Optical Emission Spectroscopy, to monitor the light emission from the species produced in the molecular-propelled HET and trace their birth location.

4.2.2. Effect of the propellant flow ratio. The spectra in Figure 11 shows the effect of varying the propellant flow rate as the anode power is kept constant. In Figure 11a, the propellants flow rates were chosen so that the discharge current remains constant for a given anode voltage (therefore the scans are for a constant anode power). The anode voltage and current are $290 \mathrm{~V}$ and $2.35 \mathrm{~A}$, respectively, corresponding to an anode power of $681.5 \mathrm{~W}$. We see that as the ratio of the Xe-to- $\mathrm{N}_{2}$ flow rate decreases, the nitrogen species contribution to the ion current increases. At this power, we were able to lower the Xe flow to $0.16 \mathrm{mg} / \mathrm{s}$ (at an $\mathrm{N}_{2}$ flow rate of $1.33-1.39 \mathrm{mg} / \mathrm{s}$ ). Attempts to 


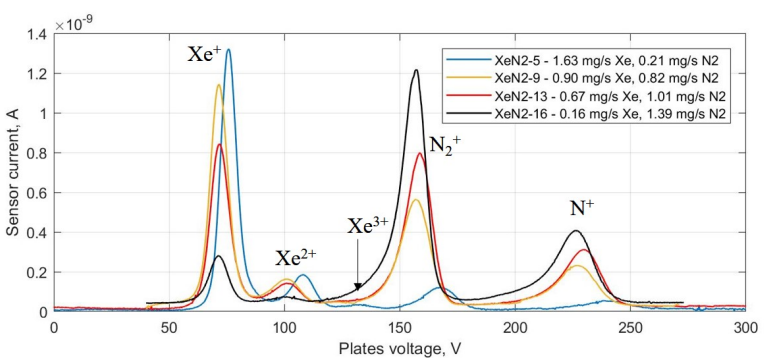

(a)

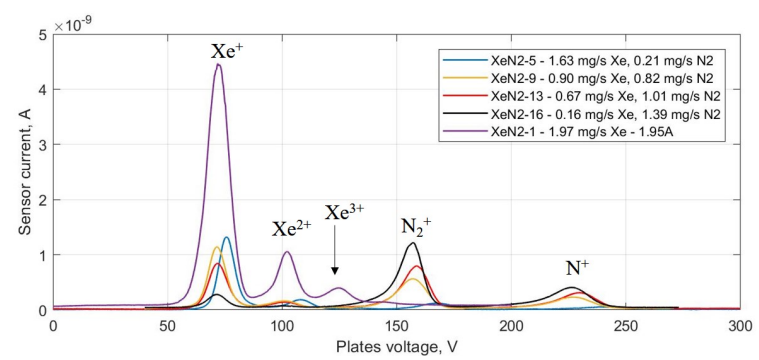

(b)

Figure 11: Uncorrected Wien filter spectra at various mixtures flow rates and fixed discharge voltage. Panel (b) contains and compare the $\mathrm{Xe} / \mathrm{N}_{2}$ spectra (shown in panel (a)) with the Xe only case (magenta line).

lower the xenon flow rate further resulted in unstable operation, eventually extinguishing the discharge. One apparent feature in the top panel is that there seems to be a more extended low energy tail in the nitrogen peaks. The broadening of the peaks, in general (as recorded previously in Xe-propelled HET [54]), is attributable to a combination of two factors: the presence of a range of acceleration voltages within the thruster channel (due to ionization occurring over a large range in potential) and ion scattering in the plume. These phenomena seem to have a more pronounced effect on the nitrogen ions. As discussed in section 2.1, the resolution of the Wien filter worsens as the voltage of the plates (Wien velocity) is increased, allowing a wider portion of the ion velocity distribution function to be recorded at a single point of the Wien filter spectrum. Consequentially, a wider peak in the Wien filter spectrum is expected at higher ion velocities. However, in our case the resolution of the $\mathrm{Xe}$ and $\mathrm{N}_{2}$ peaks are similar and so this broadening is likely due to the distributed ionization and scattering in the thruster channel and plume, affecting nitrogen and xenon differently.

In Figure 11b, we compare the spectra shown in Figure 11a to that of a pure xenon case (magenta line, XeN2-1), obtained for a xenon flow of $1.97 \mathrm{mg} / \mathrm{s}$, anode voltage of $290 \mathrm{~V}$ (as for the other runs) and anode current of $1.95 \mathrm{~A}$. Even though the anode power of the pure xenon case is somewhat lower than that of the

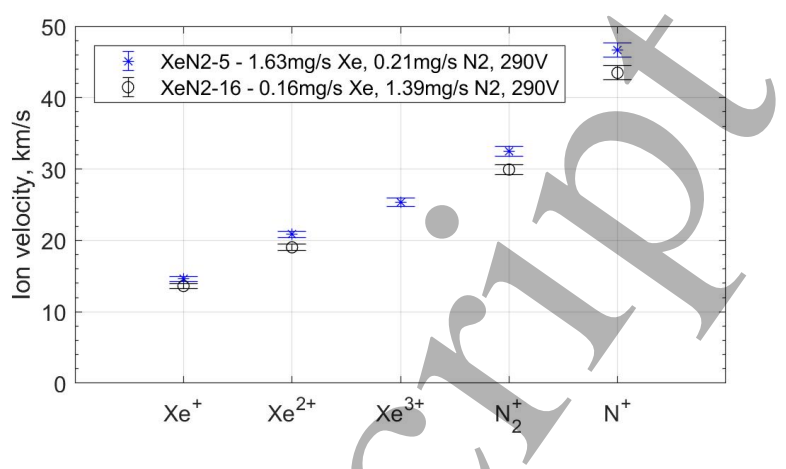

Figure 12: Ion velocities derived from the XeN2-5 and $\mathrm{XeN} 2-16$ spectra: fixed anode power $(681.5 \mathrm{~W})$ and different Xe-to- $\mathrm{N}_{2}$ mass flow rate.

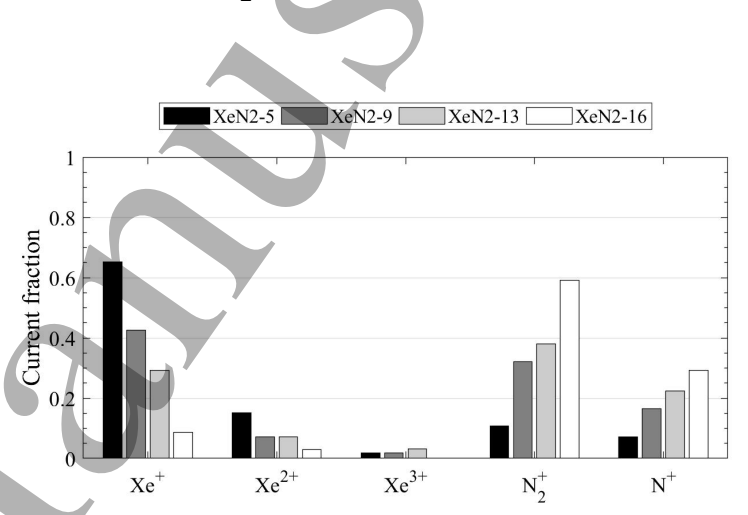

Figure 13: Current fraction at various Xe-to- $\mathrm{N}_{2}$ mass flow rate ratio at a given anode power of $681.5 \mathrm{~W}$.

mixtures $\left(681.5 \mathrm{~W}\right.$ for the Xe/ $\mathrm{N}_{2}$ mixtures and $565.5 \mathrm{~W}$ for pure Xe), its peaks (magenta line) are higher than those of the $\mathrm{Xe} / \mathrm{N}_{2}$ mixture cases. This reflects the fact that the Z-70 thruster is optimised for running with $\mathrm{Xe}$ as a propellant and is expected to perform poorly (lower total ion current) with nitrogen, as predicted by computer simulations $[55,56]$. This poorer performance is due to several effects, including a higher nitrogen ionisation cost, lower ionisation fraction due to the lower resident time of nitrogen within the discharge channel, and possibly higher plume divergence. All these processes contribute to the lower ion current density measured for nitrogen in comparison with the xenon benchmark at the same special location of the filter.

Figure 12 plots the (most probable) ion velocities for two mass flow conditions (and constant discharge voltage). At a higher Xe mass flow rate (XeN2-5), most probable ion velocities are generally higher, indicative of a higher overall thruster efficiency.

Figure 13 provides species fractional contribution to the current density and Figure 14 provides the species fractional contribution to the ion density, for the cases shown in Figure 11a. These are calculated 


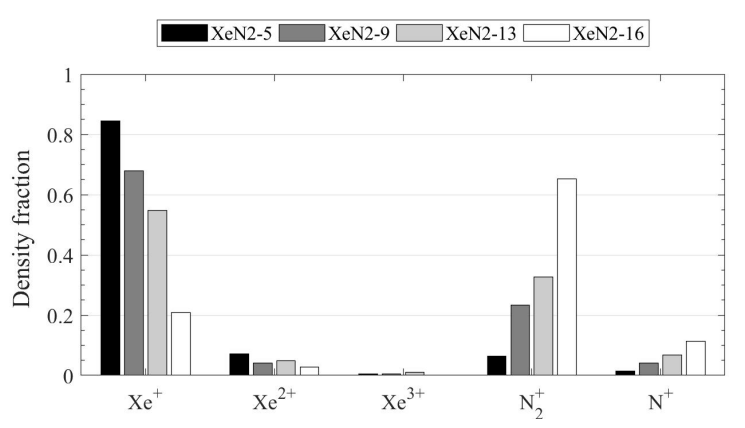

Figure 14: Ion density fraction at various Xe-to- $\mathrm{N}_{2}$ mass flow rate ratio at a given anode power of $681.5 \mathrm{~W}$.

using (11) and (12) and depicted as bar charts in the figures. As expected, the dominant contributions are sensitive to the propellant mixture. These fractions allow for an estimate of each ion species contribution to the performance metrics of the thruster (e.g. thrust, specific impulse, anode efficiency) [37].

4.2.3. Effect of the $N_{2}$ flow rate. Figure 15 describes how the ion spectra evolve when the nitrogen flow is increased, holding xenon flow rate and anode voltage constant. The xenon flow rates are $0.67 \mathrm{mg} / \mathrm{s}$ and $0.16 \mathrm{mg} / \mathrm{s}$ in the top and bottom panel of Figure 15, respectively. A close inspection of the spectra reveals that the increase in nitrogen flow slightly perturbs the xenon peaks, while having a more pronounced effect on the nitrogen peaks. Figure 16 provides a comparison of the ion velocities for runs XeN2-11 and XeN213. The ion acceleration voltages calculated from the spectra of case XeN2-13 are shown in Figure 17. As seen previously, the $\mathrm{N}^{+}$ions have acceleration voltages higher than that of $\mathrm{Xe}^{+}$.

4.2.4. Effect of the Xe flow ratê. Figure 18 shows how the xenon flow rate influences the spectra while the nitrogen flow rate and anode voltage are held constant at $0.82 \mathrm{mg} / \mathrm{s}$ and $290 \mathrm{~V}$, respectively. The peaks that are mainly affected by a change in the Xe flow rate are those of $\mathrm{Xe}^{+}$and $\mathrm{N}_{2}^{+}$and, interestingly, the $\mathrm{N}_{2}^{+}$ peak increases when the Xe flow rate is reduced from $0.90 \mathrm{mg} / \mathrm{s}$ to $0.80 \mathrm{mg} / \mathrm{s}$. An opposite trend is seen for the $\mathrm{Xe}^{+}$peak, which decreases as the Xe flow rate is reduced. A possible explanation for this could be that the electron temperature and density change within the thruster channel and, consequently, affect the ionisation rate coefficient for the production of $\mathrm{N}_{2}^{+}$.

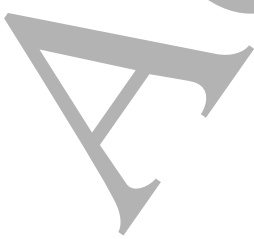

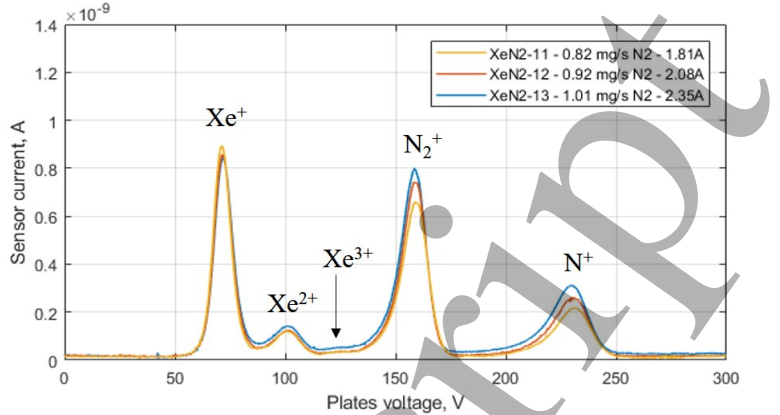

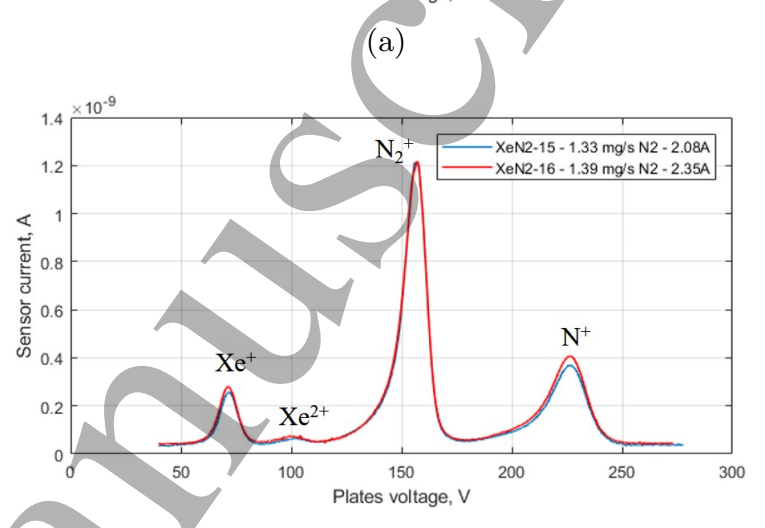

(b)

Figure 15: Uncorrected Wien filter spectra at various $\mathrm{N}_{2}$ flow rates and fixed anode voltage. The anode voltage is $290 \mathrm{~V}$. On the top right corner of each plot, the legend shows the experiment number, the $\mathrm{N}_{2}$ flow rate and anode current.

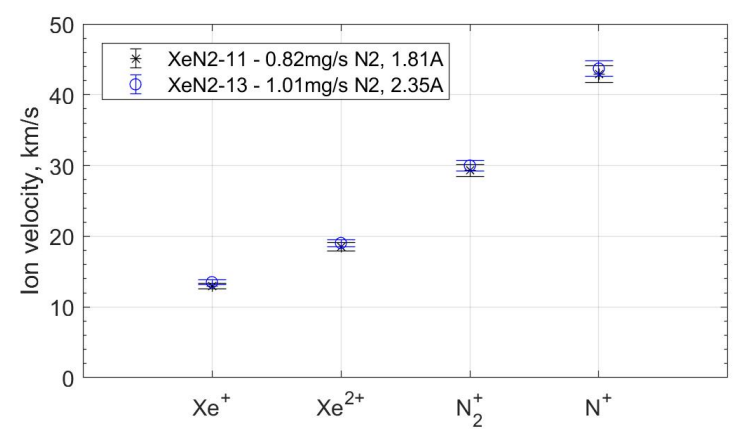

Figure 16: Ion velocities derived from the XeN2-11 and XeN2-13 spectra. The anode voltage is $290 \mathrm{~V}$ and the xenon mass flow is $0.67 \mathrm{mg} / \mathrm{s}$. 


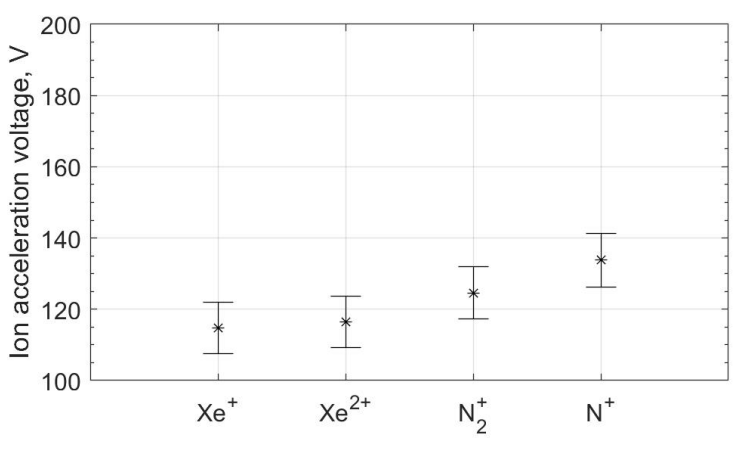

Figure 17: Ion acceleration voltages derived from the XeN2-13 spectrum. The anode voltage and current are $290 \mathrm{~V}$ and $2.35 \mathrm{~A}$, respectively, the xenon and nitrogen mass flow rates are $0.67 \mathrm{mg} / \mathrm{s}$ and $1.01 \mathrm{mg} / \mathrm{s}$, respectively.

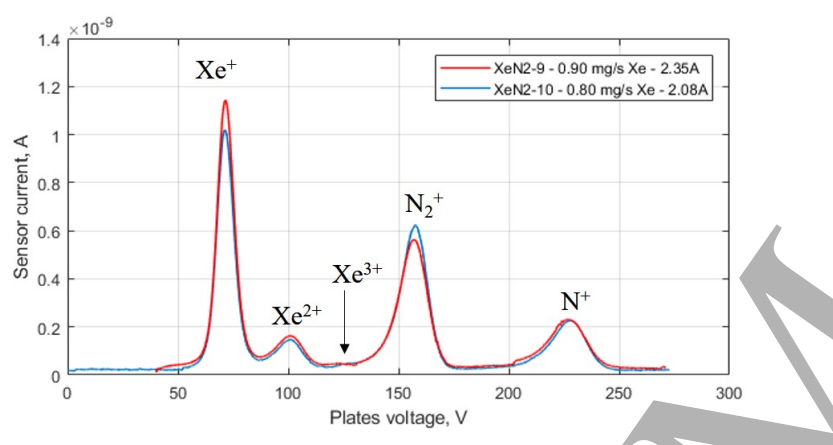

Figure 18: Uncorrected Wien filter spectra at various $\mathrm{Xe}$ flow rates and fixed anode voltage. The $\mathrm{N}_{2}$ flow rate is $0.82 \mathrm{mg} / \mathrm{s}$ and the anode voltage is $290 \mathrm{~V}$.

\subsection{Xe/air mixture}

In this section we present results of studies when the thruster propellant is a mixture of $\mathrm{Xe} / \mathrm{air}$. The main ion species observed are $\mathrm{Xe}^{+}, \mathrm{Xe}^{2+}, \mathrm{Xe}^{3+}, \mathrm{O}_{2}^{+}, \mathrm{O}^{+}$, $\mathrm{N}_{2}^{+}$and $\mathrm{N}^{+}$. Since the oxygen and nitrogen have masses of $16 \mathrm{amu}$ and $14 \mathrm{amu}$, respectively ( $1 \mathrm{amu}$ is the atomic mass unit, $1.66 \cdot 10^{-27} \mathrm{~kg}$ ), it is expected that the oxygen peaks (atomic or molecular) are at lower velocities than those of nitrogen (atomic or molecular).

To estimate the expected ion peak height of $\mathrm{O}_{2}$ and $\mathrm{N}_{2}$ ion species, the ionisation rate coefficient of $\mathrm{O}_{2}$ and $\mathrm{N}_{2}$ are calculated using the Bolsig + software [57], including various collision cross sections (elastic, ionisation) taken from the Biagi database [58]. Bolsig+ is a Boltzmann equation solver used to calculate the electron energy distribution function and rate coefficients. The simulation parameters include the reduced angular frequency (to account for magnetised electrons within the $\mathbf{E} \times \mathbf{B}$ region of the HET and defined as the ratio of angular cyclotron frequency of

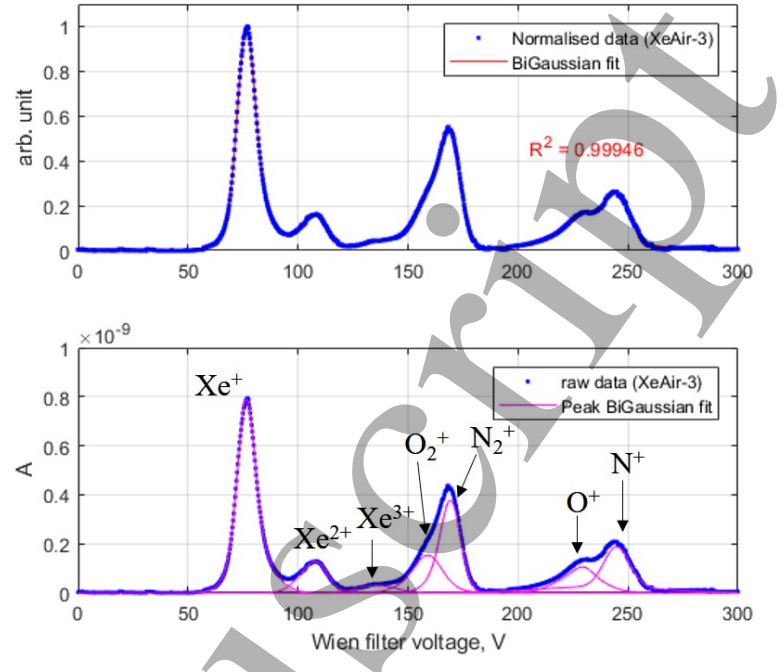

Figure 19: Example of spectrum fitting of the run XeAir-3. The set of fitting distribution functions is BiGaussian.

magnetized electrons to gas particle number density), taken to be $4.6 \cdot 10^{-15} \mathrm{rad} \mathrm{m}^{3} / \mathrm{s}$, the gas temperature of $473.15 \mathrm{~K}$, the total neutral density of $10^{19} \mathrm{~m}^{-3}$, the ratios of the species densities to the total density, $n_{\mathrm{Xe}} / n_{\text {tot }}=0.54, n_{\mathrm{N}_{2}} / n_{\text {tot }}=0.3588, n_{\mathrm{O}_{2}} / n_{\text {tot }}=$ 0.0966 , and $n_{\mathrm{Ar}} / n_{\text {tot }}=0.0046$ for Xe, $\mathrm{N}_{2}, \mathrm{O}_{2}$ and $\mathrm{Ar}$, respectively. The partial neutral density is estimated from the flow rate of xenon $(1.97 \mathrm{mg} / \mathrm{s})$ and of air $(0.09 \mathrm{mg} / \mathrm{s})$, where the composition of air is assumed to be $78 \% \mathrm{~N}_{2}, 21 \% \mathrm{O}_{2}$ and $1 \%$ Ar. The result shows that the ionisation rate coefficients of $\mathrm{O}_{2}$ and $\mathrm{N}_{2}$ are very close in value (within a $3 \%$ interval) within the mean electron energy range of $1-50 \mathrm{eV}$. Therefore, we expect that the peaks of the ionised species of $\mathrm{O}_{2}$ will have lower heights in comparison with $\mathrm{N}_{2}$ species peaks due to the lower density, but still within the detection range of the instrument. A representative measured spectrum and associated peak (BiGaussian) fits are shown in Figure 19. Indeed, oxygen species appear at slightly lower Wien filter voltage, with lower intensities.

4.3.1. Effect of the air flow rate. Figure 20 compares the changes seen in the spectra when a small amount of air is added to a constant pure xenon flow. We see a drastic reduction in the Xe species peaks and the emergence of a small peak at plate voltages where $\mathrm{N}_{2}^{+}$and $\mathrm{O}_{2}^{+}$are expected. In these two runs (XeAir1 and XeAir-2) an additional peak is observed at a plate voltage of $60-65 \mathrm{~V}$. This peak is prominent in the case pure Xe (XeAir-1) and appears to shift to higher voltage when air is added, merging with the $\mathrm{Xe}^{+}$ peak. A similar lower voltage feature was reported in 


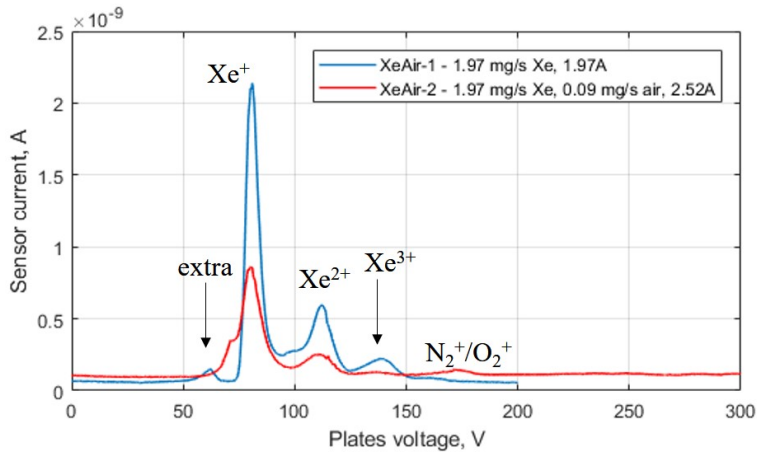

Figure 20: Uncorrected Wien filter spectra of run numbers XeAir-1 and XeAir-2 at various air flow rates and fixed anode voltage. The Xe flow rate is $1.97 \mathrm{mg} / \mathrm{s}$ and the anode voltage is $290 \mathrm{~V}$. On the top right corner, the legend shows the experiment number, the Xe flow rate, the air flow rate and anode current.

previous angular resolved Wien filter spectrum studies in the Busek-200-X3 thruster [27]. Although the cause for the appearance of this feature has not yet been determined, the previous study showed a dependence on the angular location of the line of sight of the Wien filter (relative to the thruster axis), suggesting a slight misalignment of the probe in our setup during this specific run. The misalignment also causes an overall decrease of the collected ion current and this is evident when comparing spectrum XeAir-1 (probe misaligned) in Figure 20 with spectrum XeN2-1 (probe aligned correctly) in Figure 6, in which the thruster operational conditions are similar.

4.3.2. Effect of the magnetic field. The radial magnetic flux density in the thruster channel is expected to indirectly influence the ion dynamics. Figure 21 shows a comparison of two Wien filter spectra when the xenon flow rate is $0.78 \mathrm{mg} / \mathrm{s}$, the air flow rate is $0.83 \mathrm{mg} / \mathrm{s}$ and the anode voltage is 290 V. In run XeAir-3 (blue line) the radial magnetic flux density is about $135 \mathrm{G}$ and in run XeAir-4 (red line), about $160 \mathrm{G}$. An increase of the radial magnetic flux density has two effects: (i) it decreases the anode current, due to a reduction of the electron transport transversal to the magnetic field lines, and (ii) slightly decelerates the ions to lower velocities, likely due to a reconfiguration of the acceleration voltage region within the thruster channel.

4.3.3. Comparison of Xe/air and Xe/N2 spectra. Figure 22 provides a comparison between spectra acquired with Xe/air (XeAir-3) and Xe/N2 (XeN2-10) propellant mixtures. The particular cases shown are chosen because the xenon and molecular gas flow rates

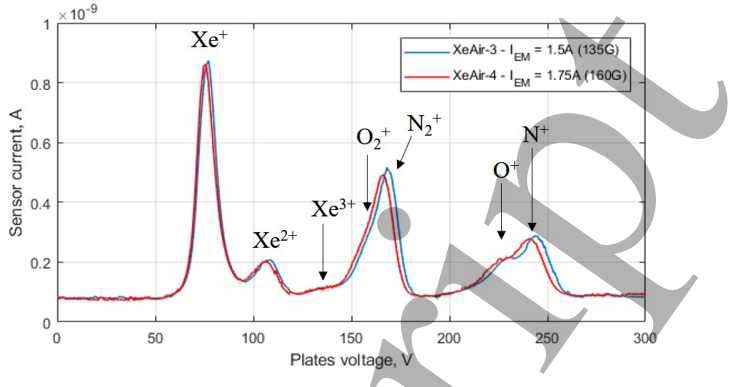

Figure 21: Uncorrected Wien filter/spectra of run numbers XeAir-3 and XeAir-4 at two radial magnetic flux densities in the thruster channel. The Xe flow rate is $0.78 \mathrm{mg} / \mathrm{s}$, air flow rate is $0.83 \mathrm{mg} / \mathrm{s}$ and the anode voltage is $290 \mathrm{~V}$. On the top right corner, the legend shows the experiment number, the electromagnet current and the radial magnetic flux density on the centreline of the Z-70 channel (in brackets). The anode current is $2.57 \mathrm{~A}$ and $2.45 \mathrm{~A}$ for runs XeAir-3 and XeAir-4, respectively.

are similar as are the discharge voltages. For these operating conditions, the discharge power is higher for the case where the working gas mixture comprises air. We also note that while the peaks of the xenon species are located at the same voltages in both runs, the nitrogen peaks appear at higher plate voltages (ion velocities) in the run with air (XeAir-3) compared to that with just nitrogen (XeN2-10). As expected, the oxygen contribution appears on the lower voltage wing of the nitrogen peaks. With the air mixture, the fitting procedure is performed with extra care as the oxygen and nitrogen peaks blend into each other (see also Figure 19). The patterns seen in these data support the assignment of the knee on the lower voltage side of the nitrogen peaks to be that contribution from oxygen ions. For example, as mentioned above, oxygen species are heavier than that of nitrogen, and, thus, are expected to be accelerated to a lower velocity. Also, molecular nitrogen is more abundant than molecular oxygen in air, and thus should have a higher signal due to their similar ionisation rate coefficients.

The most probable ion velocity and ion acceleration voltage derived from the XeAir-3 spectrum are shown in Figure 23 and Figure 24, respectively. The mean velocities of the ion species are $14 \mathrm{~km} / \mathrm{s}$ $\left(\mathrm{Xe}^{+}\right), 20 \mathrm{~km} / \mathrm{s}\left(\mathrm{Xe}^{2+}\right), 26 \mathrm{~km} / \mathrm{s} \quad\left(\mathrm{Xe}^{3+}\right), 30 \mathrm{~km} / \mathrm{s}$ $\left(\mathrm{O}_{2}^{+}\right), 32 \mathrm{~km} / \mathrm{s}\left(\mathrm{N}_{2}^{+}\right), 44 \mathrm{~km} / \mathrm{s}\left(\mathrm{O}^{+}\right)$and $47 \mathrm{~km} / \mathrm{s}\left(\mathrm{N}^{+}\right)$. We see that the acceleration voltages of all of the ionic molecular species are comparable to that of $\mathrm{Xe}^{+}$ (within the experimental uncertainty), whereas the ions $\mathrm{O}^{+}$and $\mathrm{N}^{+}$seem to experience an acceleration voltage that is slightly higher than that of $\mathrm{Xe}^{+}$. This behavior is consistent with that observed using $\mathrm{Xe} / \mathrm{N}_{2}$ 


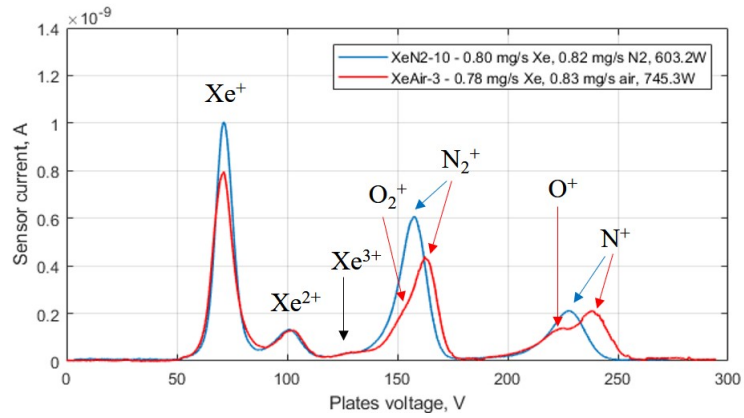

Figure 22: Comparison of the uncorrected Wien filter spectra of run numbers XeN2-10 and XeAir-3. The anode voltage is $290 \mathrm{~V}$. On the top right corner, the legend shows the experiment number, the Xe flow rate, the molecular gas flow rate and the anode power.

mixtures. As previously mentioned, a potential underlying explanation is related to discharge fluctuations, depicted in Figure 25 which shows discharge current traces recorded by means of a Rogowski coil and associated Fast Fourier Transforms (FFT) for various operating conditions. In runs XeAir-1 and XeAir-2 the xenon flow rate is the same $(1.97 \mathrm{mg} / \mathrm{s})$ while the air flow is increased from 0 to $0.09 \mathrm{mg} / \mathrm{s}$. The Fourier spectra show a main quasi-periodic oscillation at a frequency of $21-22 \mathrm{kHz}$ and its higher harmonics, together with other high-frequency fluctuations. The amplitude of the current oscillations decreases as air is injected. If the quantity of air is further increased with respect to that of xenon, the strongest oscillation frequency increases, however the main harmonic spectral feature is less defined and the Fourier spectrum presents a more significant broadband frequency content. This is the case of runs XeAir-3 and XeAir- 4 where the xenon and air flow rates are 0.78 and $0.83 \mathrm{mg} / \mathrm{s}$, respectively. In Hall Thrusters operated on xenon, LaserInduced Fluorescence measurements synchronized with discharge current oscillations have shown that the dynamic ion flow field originates from the interplay between time-dependent ionisation and time-varying potential profile $[47,59]$. This framework can be extended to multi-species plasmas operated on air, however with increased complexity. Ionisation of the different species can take place in different spatial locations and at different phases of the discharge current fluctuations, with overall combinations of time-dependent ionisation and potential profile that can result in different average acceleration voltages for the various species. The assessment of this physical framework would need either measurements in the discharge channel and near-field plume or dedicated simulations.

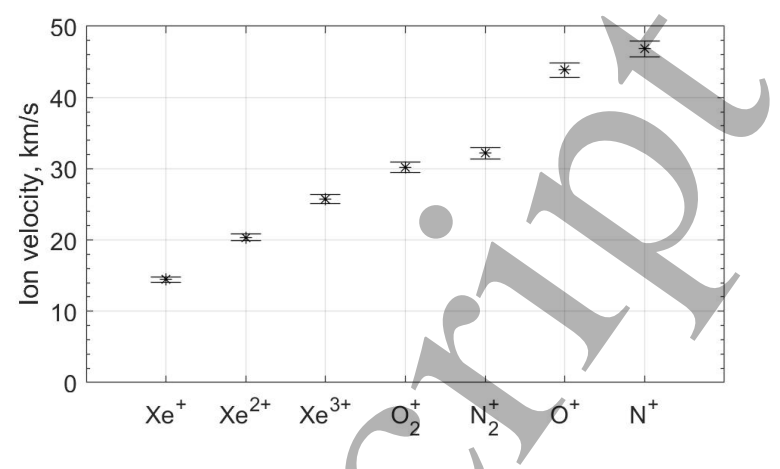

Figure 23: Ion velocity derived from the XeAir-3 spectrum. The anode voltage and current are $290 \mathrm{~V}$ and $2.57 \mathrm{~A}$, respectively, the xenon and air mass flow rates are $0.78 \mathrm{mg} / \mathrm{s}$ and $0.83 \mathrm{mg} / \mathrm{s}$, respectively.

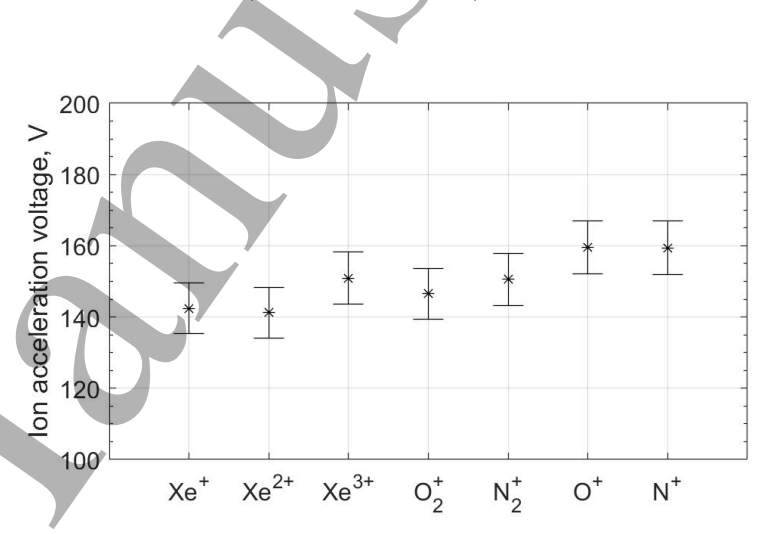

Figure 24: Ion acceleration voltage derived from the XeAir-3 spectrum. The anode voltage and current are $290 \mathrm{~V}$ and $2.57 \mathrm{~A}$, respectively, the xenon and air mass flow rates are $0.78 \mathrm{mg} / \mathrm{s}$ and $0.83 \mathrm{mg} / \mathrm{s}$, respectively.

4.3.4. Current and density ratios. The ion density and ion current fractions contributed by the various ion species, calculated according to (11) and (12), respectively, are shown in Figure 26 (for the cases XeN2-1, XeN2-16 and XeAir-3). The results depicted in Figure 26a reveals that when the thruster operates on pure $\mathrm{Xe}$ (XeN2-1 - black bars), $\mathrm{Xe}^{+}$is the main contributor to the ion current, with a fraction of 0.76 . This is followed by $\mathrm{Xe}^{2+}(0.16)$ and $\mathrm{Xe}^{3+}(0.08)$. In our experiments, we could not resolve any contributions from $\mathrm{Xe}^{4+}$. The density fraction (Figure $26 \mathrm{~b}$ ) for $\mathrm{Xe}^{+}$, $\mathrm{Xe}^{2+}$, and $\mathrm{Xe}^{3+}$, is $0.91,0.08$, and 0.02 , respectively. When operating on mixtures of Xe and $\mathrm{N}_{2}$ (run XeN216 - dark grey bars) with mass flow rates of $0.16 \mathrm{mg} / \mathrm{s}$ and $1.39 \mathrm{mg} / \mathrm{s}$, respectively, the ions species whose parent neutral is $\mathrm{N}_{2}$ dominate the contribution to the current and density fractions. The current fraction is 0.59 for $\mathrm{N}_{2}^{+}$and 0.29 for $\mathrm{N}^{+}$, while $\mathrm{Xe}^{+}$and $\mathrm{Xe}^{2+}$ contributions are 0.08 and 0.04 , respectively. The $\mathrm{Xe}^{3+}$ has a negligible influence on the measured parameters. 

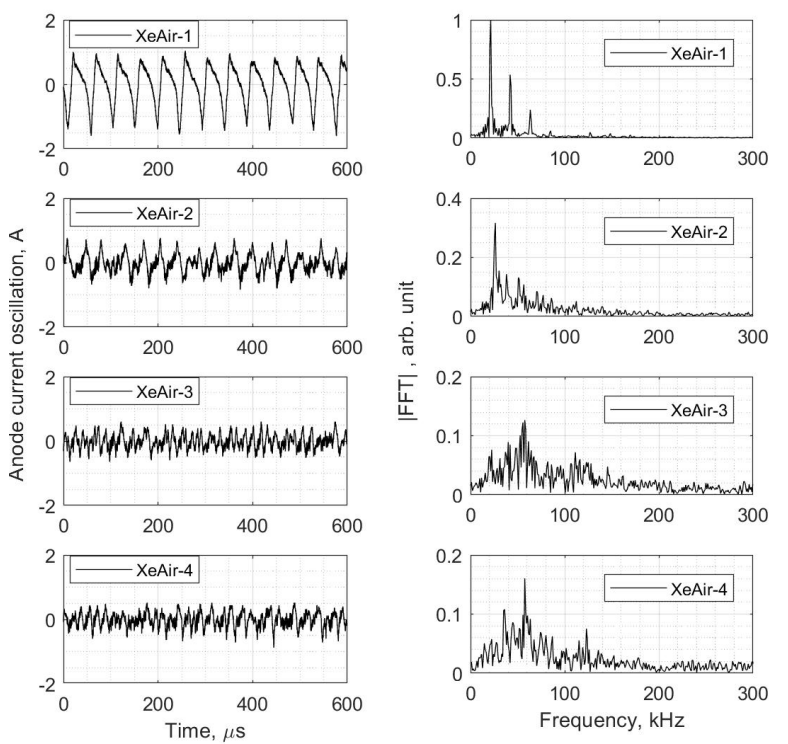

Figure 25: Anode current oscillation and FFT (normalised to the maximum value encountered in XeAir-1) of the current signal acquired during runs XeAir-1, XeAir-2, XeAir-3 and XeAir-4. In runs XeAir-1 and XeAir-2 the injected air flow rate is $0 \mathrm{mg} / \mathrm{s}$ and $0.09 \mathrm{mg} / \mathrm{s}$, respectively, and the xenon flow rate is $1.97 \mathrm{mg} / \mathrm{s}$. In both runs XeAir-3 and XeAir-4, the xenon and air flow rates are $0.78 \mathrm{mg} / \mathrm{s}$ and $0.83 \mathrm{mg} / \mathrm{s}$, respectively, while a stronger magnetic field is applied in run XeAir-4.

The highest density fraction is $0.58\left(\mathrm{~N}_{2}^{+}\right)$, followed by $0.20\left(\mathrm{~N}^{+}\right), 0.18\left(\mathrm{Xe}^{+}\right)$, and $0.04\left(\mathrm{Xe}^{2+}\right)$. Finally, with mixtures of Xe and air, (XeAir-3 -light grey bars) at propellant mass flow rates of $0.78 \mathrm{mg} / \mathrm{s}$ and $0.83 \mathrm{mg} / \mathrm{s}$, respectively, we have the most complex spectra with seven different ion species detected by the Wien filter, i.e. $\mathrm{Xe}^{+}, \mathrm{Xe}^{2+}, \mathrm{Xe}^{3+}, \mathrm{O}_{2}^{+}, \mathrm{N}_{2}^{+}, \mathrm{O}^{+}$and $\mathrm{N}^{+}$. Here, we find that $\mathrm{Xe}^{+}$has the most prevailing fractions, followed by $\mathrm{N}_{2}^{+}$and $\mathrm{N}^{+}$. The contributions from $\mathrm{O}_{2}^{+}$ and $\mathrm{O}^{+}$are always lower than those of $\mathrm{N}_{2}^{+}$and $\mathrm{N}^{+}$, respectively.

\section{Conclusions}

We have operated a Hall effect thruster on mixtures of $\mathrm{Xe} / \mathrm{N}_{2}$ and $\mathrm{Xe} /$ air to investigate the composition of the ion plume using a Wien filter (or $\mathbf{E} \times \mathbf{B}$ probe). The Wien filter spectra were acquired over a broad range of operating conditions, varying anode voltage and power, mass flow rates, and magnetic field. The most probable ion velocity and ion acceleration voltage have been determined, accounting for the potential drop between the plume plasma (at plasma potential) and the Wien filter internal axis, as well as the drift
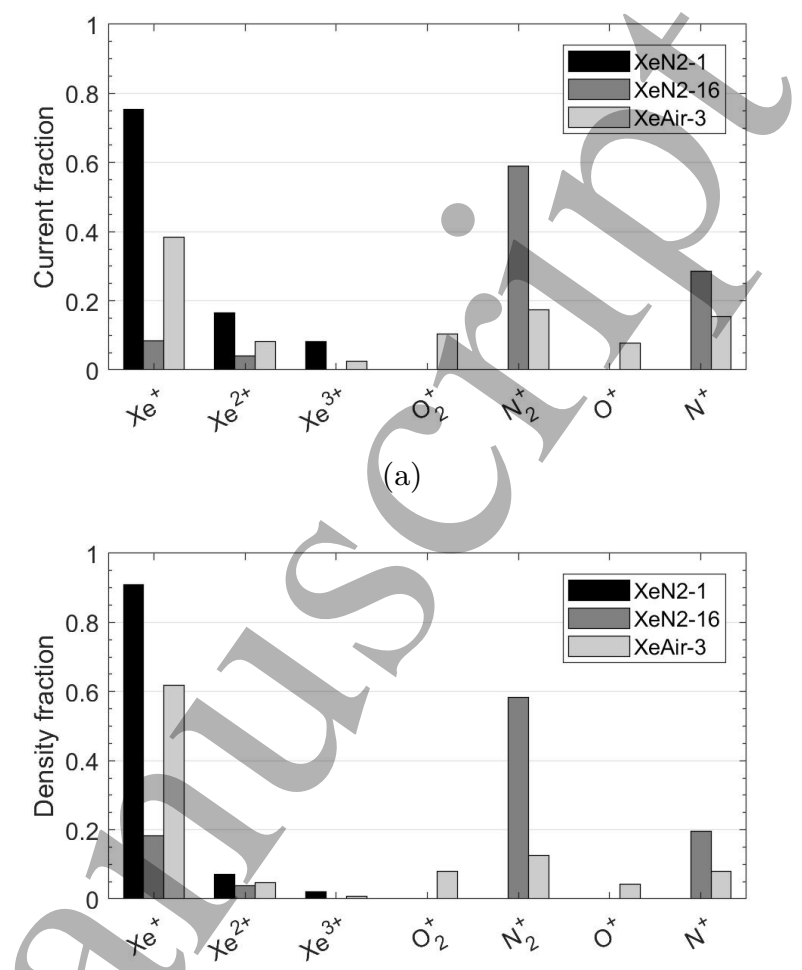

(b)

Figure 26: (a) Current and (b) density ratios of run XeN2-1 (Xe mass flow rate of $1.97 \mathrm{mg} / \mathrm{s}$ and anode power of $565.5 \mathrm{~W}$ ), XeN2-16 (Xe mass flow rate of $0.16 \mathrm{mg} / \mathrm{s}$, $\mathrm{N}_{2}$ mass flow rate of $1.39 \mathrm{mg} / \mathrm{s}$ and anode power of $681.5 \mathrm{~W}$ ) and XeAir-3 (Xe mass flow rate of $0.78 \mathrm{mg} / \mathrm{s}$, air mass flow rate of $0.83 \mathrm{mg} / \mathrm{s}$ and anode power of $745.3 \mathrm{~W})$.

of the voltage along the Wien filter axis due to electric circuit imperfections. Monte Carlo simulations allowed us to estimate uncertainties of the measured quantities, deriving from introduced the uncertainties in various filter parameters.

One unexpected result is that the lighter ion species $\left(\mathrm{N}^{+}\right.$and $\left.\mathrm{O}^{+}\right)$appear to experience acceleration voltages that are higher than that of $\mathrm{Xe}^{+}$. This seems counterintuitive for several reasons, since lighter neutrals have shorter residence times through the ionization region within the discharge channel and, even more so since measured cross sections (e.g. for $\mathrm{N}_{2}$ ) indicate that direct ionization should be more favourable over dissociative ionization [60]. This peculiar finding needs to be further examined.

Finally, the contributions of the various plume ion species to the total ion current and density have been determined. The measured fractions can provide an estimate of the influence that each species may have on the performance of a Hall Effect Thruster that operates on nitrogen or air-containing mixtures. 
We note that the thruster studied here was designed and optimized to operate efficiently on xenon, however, these results can serve as an appropriate starting point to further explore the design modifications that might be appropriate for optimized operation with molecular propellants.

\section{Acknowledgements}

This research is supported in part by the Air Force Office of Scientific Research. A.G. would like to thank Surrey Satellite Technology Ltd for support provided through a PhD studentship. The authors would like to acknowledge N. Gascon for advice provided throughout the course of these studies.

\section{References}

[1] N. C. Wallace, "Testing of the QinetiQ T6 thruster in support of the ESA BepiColombo Mercury mission," in 4th International Spacecraft Propulsion Conference, no. 2-4 June, (Cagliari, Italy), pp. ESA SP-555, 2004.

[2] J. R. Anderson, K. D. Goodfellow, J. E. Polk, V. K. Rawlin, and J. S. Sovey, "Performance characteristics of the NSTAR ion thruster during an on-going long duration ground test," IEEE Aerospace Conference Proceedings, vol. 4, no. January, pp. 99-121, 2000.

[3] N. Wallace, P. Jameson, C. Saunders, M. Fehringer, C. Edwards, and R. Floberghagen, "The GOCE Ion Propulsion Assembly - Lessons Learnt from the First 22 Months of Flight Operations," in 32nd International Electric Propulsion Conference, no. 11-15 September, (Wiesbaden, Germany), pp. IEPC-2011-327, 2011.

[4] C. R. Koppel and D. Estublier, "The SMART1 electric propulsion subsystem," in 39th AIAA/ASME/SAE/ASEE Joint Propulsion Conference and Exhibit, no. 20-23 July, (Huntsville, Alabama, USA), pp. AIAA 2003-4545, 2003.

[5] R. Betzendahl, "The 2014 Rare Gases Market Report," CryoGas International, no. July, pp. 28-30, 2014.

[6] R. P. Welle, "Xenon and krypton availability for electric propulsion - An updated assessment," in 29th Joint Propulsion Conference and Exhibit, (Monterey, California, USA), pp. AIAA 93-2401, 1993.

[7] F. Paganucci, M. M. Saravia, M. Mininni, L. Bernazzani, A. Ceccarini, T. Boulzaguet, G. Pellegrini, C. Ducci, D. Pedrini, T. Andreussi, and N. Kutufà, "Progress on the Development of an Iodine-fed Hall Effect Thruster," in 35th International Electric Propulsion Conference, (Atlanta, Georgia, USA), pp. IEPC-2017-418, 2017.

[8] M. Tsay, J. Frongillo, J. Zwahlen, and L. Paritsky, "Maturation of Iodine Fueled BIT-3 RF Ion Thruster and RF Neutralizer," in 52nd AIAA/SAE/ASEE Joint Propulsion Conference, no. 25-27 July, (Salt Lake City, Utah, USA), pp. AIAA 2016-4544, 2016.

[9] T. Andreussi, G. Cifali, V. Giannetti, A. Piragino, E. Ferrato, A. Rossodivita, M. Andrenucci, J. Longo, and L. Walpot, "Development and Experimental Validation of a Hall Effect Thruster RAM-EP Concept," in 35th International Electric Propulsion Conference, (Atlanta, Georgia, USA), pp. IEPC-2017-377, 2017.

[10] S. Barral, G. Cifali, R. Albertoni, M. Andrenucci, and L. Walpot, "Conceptual design of an air-breathing electric propulsion system," in 30th International
Electric Propulsion Conference, no. 7-10 July, (HyogoKobe, Japan), pp. IEPC-2015-271/ISTS-2015-b-271, 2015.

[11] F. Romano, B. Massuti-Ballester, T. Binder, G. Herdrich, S. Fasoulas, and T. Schönherr, "System analysis and test-bed for an atmosphere-breathing electric propulsion system using an inductive plasma thruster," Acta Astronautica, vol. 147, no. January, pp. 114-126, 2018.

[12] K. Nishiyama, "Air breathing ion engine concept," in 54 th International Astronautical Congress, no. 29 September - 3 October, (Bremen, Germany), pp. IAC-03-S.4.-02, 2003.

[13] K. Hohman, "Atmospheric breathing electric thruster for planetary exploration." https://www.nasa.gov/pdf/636899main_ Hohman_Presentation.pdf [Accessed: 03 October 2018], 2012.

[14] L. Pekker and M. Keidar, "Analysis of Airbreathing HallEffect Thrusters," Journal of Propulsion and Power, vol. 28, no. 6, pp. 1399-1405, 2012.

[15] G. Cifali, T. Misuri, P. Rossetti, M. Andrenucci, D. Valentian, D. Feili, and B. Lotz, "Experimental characterization of HET and RIT with atmospheric propellants," in 32nd International Electric Propulsion Conference, no. 11-15 September, (Weisbaden, Germany), pp. IEPC2011-224, 2011.

[16] A. Shabshelowitz, A. D. Gallimore, and P. Y. Peterson, "Performance of a helicon hall thruster operating with xenon, argon, and nitrogen," Journal of Propulsion and Power, vol. 30, no. 3, pp. 664-671, 2014.

[17] R. R. Hofer, J. M. Haas, and A. D. Gallimore, "Ion Voltage Diagnostics in the Far-Field Plume of a HighSpecific Impulse Hall Thruster," in 39th Joint Propulsion Conference and Exhibit, no. July 20-23, (Huntsville, Alabama), pp. AIAA-2003-4556, 2003.

[18] I. H. Hutchinson, Principles of Plasma Diagnostics. Cambridge: Cambridge University Press, 5 ed., 2005.

[19] R. R. Hofer and A. D. Gallimore, "High-Specific Impulse Hall Thrusters, Part 2: Efficiency Analysis," Journal of Propulsion and Power, vol. 22, no. 4, pp. 732-740, 2006.

[20] H. Kamhawi, W. Huang, J. Gilland, T. Haag, J. Mackey, J. Yim, L. Pinero, G. Williams, P. Peterson, and D. Herman, "Performance, Stability, and Plume Characterization of the HERMeS Thruster with Boron Nitride Silica Composite Discharge Channel," in 35th International Electric Propulsion Conference, no. 8-12 October, pp. IEPC-2017-392, 2017.

[21] L. King and A. Gallimore, "Ion energy diagnostics in the plume of an spt-100 from thrust axis to backflow region," in 34th AIAA/ASME/SAE/ASEE Joint Propulsion Conference and Exhibit, p. 3641, 1998.

[22] S.-W. Kim and A. D. Gallimore, "Plume study of a $1.35 \mathrm{~kW}$ SPT-100 using an E x B probe," in 35th AIAA/ASME/SAE/ASEE Joint Propulsion Conference and Exhibit,, no. 20-24 July, (Los Angeles, California, USA), pp. AIAA-1999-2423, 1999.

[23] R. P. Vahrenkamp, "Measurement of double charged ions in the beam of a 30-cm mercury bombardment thruster," in AIAA10th Electric Propulsion Conference, no. 31 October-2 November, (Lake Tahoe, Nevada, USA), pp. AIAA-73-1057, 1973.

[24] H. Takegahara, Y. Kasai, Y. Gotoh, K. Miyazaki, Y. Hayakawa, S. Kitamura, H. Nagano, and K. Nakamaru, "Beam Characteristics Evaluation of ETS-VI Xenon Ion Thruster," in 23rd AIAA/AIDAA/DGLR/JSASS International Electric Propulsion Conference, (Seattle, Washington, USA), pp. IEPC-93-235, 1993.

[25] S. W. Kim, Experimental investigation of species-dependent ion energy distribution in the plasma exhaust plume of 
Ion plume investigation of a Hall Effect Thruster operating with $\mathrm{Xe} / \mathrm{N}_{2}$ and Xe/air mixtures

a Hall Thruster. PhD thesis, University of Michigan, 1999.

[26] R. R. Hofer and A. D. Gallimore, "Ion species fractions in the far-field plume of a highspecific impulse Hall thruster," in 39th AIAA/ASME/SAE/ASEE Joint Propulsion Conference and Exhibit, no. 20-23 July, pp. AIAA-2003-5001, 2003.

[27] J. Ekholm and W. Hargus, "E x B Measurements of a 200 W Xenon Hall Thruster," in 41st AIAA/ASME/SAE/ASEE Joint Propulsion Conference \& Exhibit, no. 10-13 July, (Tucson, Arizona, USA), pp. AIAA-2005-4405, 2005.

[28] B. Reid, R. Shastry, and A. Gallimore, "AngularlyResolved ExB Probe Spectra in the Plume of a 6kW Hall Thruster," in 44th AIAA/ASME/SAE/ASEE Joint Propulsion Conference and Exhibit, no. 21-23 July, (Hartford, Connecticut, USA), pp. AIAA-2008-5287, 2008.

[29] H. Kim, Y. Lim, W. Choe, and J. Seon, "Effect of multiply charged ions on the performance and beam characteristics in annular and cylindrical type Hall thruster plasmas," Applied Physics Letters, vol. 105, no. $14,2014$.

[30] J. R. Anderson and D. Fitzgerald, "Fullerene propellant research for electric propulsion," in 32nd AIAA/ASME/SAE/ASEE Joint Propulsion Conference and Exhibit, no. 1-3 July, (Lake Buena Vista, Florida, USA), pp. AIAA 96-3211, 1996.

[31] D. Gerst, D. Renaud, S. Mazouffre, P. Chabert, and A. Aanesland, "ExB probe investigation of the PEGASES thruster ion beam in Xe and SF6," in 33rd International Electric Propulsion Conference, no. 6-10 October, (Washington, D.C., USA), pp. IEPC-2013-130, 2013.

[32] D. Renaud, D. Gerst, S. Mazouffre, and A. Aanesland, "EB probe measurements in molecular and electronegative plasmas," Review of Scientific Instruments, vol. 86, no. $12,2015$.

[33] W. Huang and R. Shastry, "Analysis of Wien filter spectra from Hall thruster plumes.," The Review of scientific instruments, vol. 86, no. 7, p. 073502, 2015.

[34] M. Á. Herrador, A. G. Asuero, and A. G. González, "Estimation of the uncertainty of indirect measurements from the propagation of distributions by using the Monte-Carlo method: An overview," Chemometrics and Intelligent Laboratory Systems, vol. 79, no. 1-2, pp. 115122,2005

[35] A. Lucca Fabris, Experimental Characterization of Plasma Sources for Space Propulsion. PhD thesis, Università degli studi di Padova, 2014.

[36] A. W. Smith, Field structure and electron transport in the near-field of coaxial Hall thrusters. PhD thesis, Stanford University, 2010. Available on: https://searchworks.stanford.edu/view/8652489 [Accessed: 30 March 2019].

[37] A. Gurciullo, Electric propulsion technologies for enabling the use of molecular propellants. PhD thesis, University of Surrey, 2018.

[38] J. W. Dankanich, M. Walker, M. W. Swiatek, and J. T. Yim, "Recommended Practice for Pressure Measurement and Calculation of Effective Pumping Speed in Electric Propulsion Testing," Journal of Propulsion and Power, vol. 33, no. 3, pp. 668-680, 2016.

[39] T. Randolph, V. Kim, H. Kaufman, K. Kozubsky, V. Zhurin, and M. Day, "Facility effects on stationary plasma thruster testing," in 23rd International Electric Propulsion Conference, pp. 1993-093, 1993.

[40] W. Huang, H. Kamhawi, R. B. Lobbia, and D. L. Brown, "Effect of background pressure on the plasma oscillation characteristics of the hivhac hall thruster," in 50th AIAA/ASME/SAE/ASEE Joint Propulsion Conference, p. 3708, 2014.

[41] M. L. R Walker, A. L. Victor, R. R. Hofer, and A. D. Gallimore, "Effect of backpressure on ion current density measurements in hall thruster plumes," Journal of Propulsion and Power, vol. 21, no. 3, pp. 408-415, 2005.

[42] K. D. Diamant, R. Liang, and R. L. Corey, "The Effects of Background Pressure on SPT-100 Hall Thruster Performance," in 50th AIAA/ASME/SAE/ASEE Joint Propulsion Conference, (Cleveland, Ohio, USA), pp. AIAA 2010-3710, 2014.

[43] N. MacDonald-Tenenbaum, Q. Pratt, M. Nakles, N. Pilgram, M. Holmes, and W. Hargus Jr, "Background pressure effects on ion velocity distributions in an spt-100 hall thruster," Journal of Propulsion and Power, vol. 35, no. 2, pp. 403-412, 2019.

[44] W. Huang, H. Kamhawi, and T. Haag, "Effect of Background Pressure on the Performance and Plume of the HiVHAc Hall Thruster," in 33rd International Electric Propulsion Conference, no. 6-10 October, (Washington, D. C., USA), pp. IEPC-2013-058, 2013.

[45] K. D. Diamant, R. Spektor, E. J. Beiting, J. A. Young, and T. J. Curtiss, "The effect of background pressure on Hall thruster operation," in 48th AIAA/ASME/SAE/ASEE Joint Propulsion Conference $\&$ Exhibit, no. 30 July - 01 August, (Atlanta, Georgia, USA), pp. AIAA 2012-3735, 2012.

[46] C. V. Young, A. Lucca Fabris, and M. A. Cappelli, "Ion dynamics in an ExB Hall plasma accelerator," Applied Physics Letters, vol. 106, no. 4, 2015.

[47] A. Lucca Fabris, C. V. Young, and M. A. Cappelli, "Timeresolved laser-induced fluorescence measurement of ion and neutral dynamics in a Hall thruster during ionization oscillations," Journal of Applied Physics, vol. 118, no. 23, 2015.

[48] D. M. Goebel and I. Katz, Fundamentals of Electric Propulsion - Ion and Hall Thrusters. Hoboken, New Jersey: John Wiley and Sons, 2008.

[49] S. Halas and B. Adamczyk, "Cross sections for the production of $\mathrm{N} 2^{\wedge}\{+\}, \quad \mathrm{N}^{\wedge}\{+\}$ and $\mathrm{N} 2^{\wedge}\{2+\}$ from nitrogen by electrons in the energy range $16600 \mathrm{eV}$," International Journal of Mass Spectrometry and Ion Physics, vol. 10, no. 2, pp. 157-160, 1972.

[50] E. Krishnakumart and K. Srivastava, "Cross sections for the production of $\mathrm{N}^{\wedge}\{+\}, \mathrm{N}^{\wedge}\{+\}+\mathrm{N}^{\wedge}\{2+\}$ and $\mathrm{N}^{\wedge}\{2+\}$ by electron impact on N2," Journal of Physics B: Atomic and Molecular Physics, vol. 23, pp. 1893-1903, 1990.

[51] Y. Itikawa, "Cross sections for electron collisions with nitrogen molecules," Journal of Physical and Chemical Reference Data, vol. 35, no. 1, pp. 31-53, 2006.

[52] S. Mazouffre, P. Echegut, and M. Dudeck, "A calibrated infrared imaging study on the steady state thermal behaviour of Hall effect thrusters," Plasma Sources Science and Technology, vol. 16, no. 1, pp. 13-22, 2007.

[53] A. Lucca Fabris, C. V. Young, and M. A. Cappelli, "Excited state population dynamics of a xenon ac discharge," Plasma Sources Science and Technology, vol. 24, no. 5, p. 055013 (11pp), 2015.

[54] R. Shastry, R. R. Hofer, B. M. Reid, and A. D. Gallimore, "Method for analyzing ExB probe spectra from Hall thruster plumes," Review of Scientific Instruments, vol. 80, no. 6, 2009.

[55] E. Cha, D. B. Scharfe, M. K. Scharfe, M. A. Cappelli, and E. Fernandez, "Hybrid simulations of hall thrusters operating on various propellants," in 31st International Electric Propulsion Conference, no. 20-24 September, (Ann Arbor, Michigan, USA), pp. IEPC-2009-075, 2009.

[56] E. Cha, Dynamic models of electron transport in Hall thruster simulations. $\mathrm{PhD}$ thesis, Stanford University, 2015. Available on: 
https://searchworks.stanford.edu/view/11391850 [Accessed: 30 March 2019].

[57] G. J. Hagelaar and L. C. Pitchford, "Solving the Boltzmann equation to obtain electron transport coefficients and rate coefficients for fluid models," Plasma Sources Science and Technology, vol. 14, no. 4, pp. 722-733, 2005.

[58] "Biagi database." www.lxcat.net [Accessed: 4 May 2018].

[59] C. Young, A. Lucca Fabris, N. MacDonald-Tenenbaum, W. Hargus, and M. Cappelli, "Time-resolved laserinduced fluorescence diagnostics for electric propulsion and their application to breathing mode dynamics," Plasma Sources Science and Technology, vol. 27, no. 9, p. 094004, 2018.

[60] A. Crowe and J. W. McConkey, "Dissociative ionization by electron impact. II. N+ and N++ from N2," Journal of Physics B: Atomic and Molecular Physics, vol. 6, no. 10, pp. 2108-2117, 1973. 